Article

\title{
Prediction of Forest Structural Parameters Using Airborne Full-Waveform LiDAR and Hyperspectral Data in Subtropical Forests
}

\author{
Xin Shen ${ }^{1}$, Lin Cao ${ }^{1, *(D)}$, Dong Chen ${ }^{2}$, Yuan Sun ${ }^{1}$, Guibin Wang ${ }^{1}$ and Honghua Ruan ${ }^{1}$ \\ 1 Co-Innovation Center for Sustainable Forestry in Southern China, Nanjing Forestry University, \\ Nanjing 210037, China; shenxin1903@gmail.com (X.S.); yuan.sun@njfu.edu.cn (Y.S.); \\ guibinwang99@163.com (G.W.); hhruan@njfu.edu.cn (H.R.) \\ 2 College of Civil Engineering, Nanjing Forestry University, Nanjing 210037, China; chendong@njfu.edu.cn \\ * Correspondence: lincao@njfu.edu.cn
}

Received: 28 September 2018; Accepted: 31 October 2018; Published: 2 November 2018

\begin{abstract}
Accurate acquisition of forest structural parameters, which is essential for the parameterization of forest growth models and understanding forest ecosystems, is also crucial for forest inventories and sustainable forest management. In this study, simultaneously acquired airborne full-waveform (FWF) LiDAR and hyperspectral data were used to predict forest structural parameters in subtropical forests of southeast China. The pulse amplitude and waveform shape of airborne FWF LiDAR data were calibrated using a physical process-driven and a voxel-based approach, respectively. Different suites of FWF LiDAR and hyperspectral metrics, i.e., point cloud (derived from LiDAR-waveforms) metrics (DPC), full-waveform (geometric and radiometric features) metrics (FW) and hyperspectral (original reflectance bands, vegetation indices and statistical indices) metrics (HS), were extracted and assessed using correlation analysis and principal component analysis (PCA). The selected metrics of DPC, FW and HS were used to fit regression models individually and in combination to predict diameter at breast height $(\mathrm{DBH})$, Lorey's mean height $\left(\mathrm{H}_{\mathrm{L}}\right)$, stem number $(\mathrm{N})$, basal area $(\mathrm{G})$, volume (V) and above ground biomass (AGB), and the capability of the predictive models and synergetic effects of metrics were assessed using leave-one-out cross validation. The results showed that: among the metrics selected from three groups divided by the PCA analysis, twelve DPC, eight FW and ten HS were highly correlated with the first and second principal component $(r>0.7)$; most of the metrics selected from DPC, FW and HS had weak relationships between each other $(r<0.7)$; the prediction of $\mathrm{H}_{\mathrm{L}}$ had a relatively higher accuracy (Adjusted- $R^{2}=0.88$, relative RMSE $=10.68 \%$ ), followed by the prediction of AGB (Adjusted- $R^{2}=0.84$, relative RMSE $=15.14 \%$ ), and the prediction of $\mathrm{V}$ had a relatively lower accuracy (Adjusted $-R^{2}=0.81$, relative RMSE $=16.37 \%$ ); and the models including only DPC had the capability to predict forest structural parameters with relatively high accuracies (Adjusted- $R^{2}=0.52-0.81$, relative RMSE $=15.70-40.87 \%$ ) whereas the usage of DPC and FW resulted in higher accuracies (Adjusted- $R^{2}=0.62-0.87$, relative RMSE $=11.01-31.30 \%$ ). Moreover, the integration of DPC, FW and HS can further improve the accuracies of forest structural parameters prediction (Adjusted- $R^{2}=0.68-0.88$, relative RMSE $=10.68-28.67 \%$ ).
\end{abstract}

Keywords: LiDAR; point cloud; hyperspectral; forest structural parameters; subtropical forest

\section{Introduction}

As the dominant terrestrial ecosystem on earth, forests occupy approximately $30 \%$ of the land surface area and contribute to $75 \%$ of land gross primary production [1,2]. Subtropical forests have high diversity, dense carbon and complex structure, and cover approximately one quarter of China's 
total area. They provide valuable ecosystem goods and services to humanity and play a key role in the mitigation of climate change [3,4]. Forest structures, shaped by silvicultural practices and natural events, provide considerable information about ecosystem values such as biodiversity, water conservation and erosion control [5]. Forest structural parameters (e.g., diameter at breast height (DBH), tree height $(\mathrm{H})$, tree density $(\mathrm{N})$, basal area $(\mathrm{G})$, etc.) are essential for the parameterization of forest growth models and understanding forest ecosystems [6,7]. Timely, accurate and reliable acquisition of forest structural parameters across large areas is crucial for sustainable and multifunctional forest management [8]. Traditionally, forest structural parameters were collected using field inventory, which is labor intensive and time-consuming $[9,10]$. Remote sensing technology is able to provide detailed continuous-spatial, multi-dimensional and massive-spectral information, allowing for precise forest structural parameter prediction based on their structural and spectral signatures [11-13]. Remote sensing data have advantages such as spatial information quantification, high geometric precision and vast geographic coverage $[14,15]$, and have been used in the prediction of forest structural parameters over a range of forest types [16-18].

Light detection and ranging (LiDAR) has been applied as a promising technology for predicting forest structural parameters due to its capability to provide three-dimensional information about forest structures with high accuracy [19-21]. Airborne discrete-return LiDAR systems record multiple return signals, which contain the three-dimensional position and intensity of reflected light from each transmitted pulse. The metrics extracted from discrete point clouds represent the vertical structural characteristics of canopy such as height measures, Weibull distribution parameters, and classes of crown volume zones, etc., which can be used to predict forest structural parameters [22-24]. Forest structural parameters, i.e., H, G, V and AGB, have been predicted using discrete point cloud data in previous studies $[21,22,24,25]$. However, discrete-return systems record limited information in each returned signal, and can only detect the surfaces which are separated sufficiently in space [26]. Airborne full-waveform (FWF) LiDAR systems record the whole backscattered returns, thus they can record the geometric and biophysical attributes of forests [27]. The point cloud can be derived from FWF LiDAR data, and the number of returns extracted from FWF data is much higher than that from discrete point cloud data [28]. The waveforms obtained by full-waveform systems depend on many factors such as target backscattering characteristics, LiDAR sensor types, scan geometry [29], etc. In order to make pulse amplitude possible to be used as its true value, the pulse amplitude needs to be calibrated and corrected in full-waveform data processing [30,31]. Owing to the waveform recorded by full-waveform system being stretched by the increases of off-nadir angle and the waveforms from different trajectories often being non-vertical, the waveform processing approach needs to be developed to synthesize the raw waveforms in multiple directions into composite vertical waveforms. The full-waveform metrics (FW) extracted from FWF data describe the canopy response using parameters of waveform shape and can be applied in the prediction of forest structural parameters [13,32]. Lindberg et al. [33] extracted the amplitude of waveforms in height intervals to predict the volume in hemi-boreal forest in the southwest of Sweden, and found that the predictive model of total volume had high accuracy for waveform data (relative RMSE $=31.9 \%$ ). In the prediction of forest structural parameters (e.g., DBH, $\mathrm{H}, \mathrm{N}$ and AGB, etc.), the accuracies of predictive models were improved when using full-waveform metrics [34,35].

Hyperspectral data offer large amounts of continuous-narrow bands which contain detailed spectral signatures associated with forest biophysical properties, and which can be applied to predict forest structural parameters [16,36,37]. Airborne hyperspectral data usually have finer spatial resolution than space-borne data because airborne platforms commonly having lower altitudes than space-borne platforms [38,39]. Previous studies have demonstrated that airborne hyperspectral data perform well in forest tree species classification [40,41], and structural parameters prediction, e.g., DBH [42], tree height [43], basal area [44], stem density [23] and biomass [44-46]. The visible (VIS) and near-infrared (NIR) regions of hyperspectral narrow bands are usually considered to be correlated with forest structure properties [39,47]. Latifi et al. [23] found that a number of atmospheric 
window bands in the domains of VIS and NIR such as $540 \mathrm{~nm}, 680-730 \mathrm{~nm}$ and $970 \mathrm{~nm}$ were the most important and stable predictors of forest stem density and biomass. The hyperspectral narrow band metrics, formulated using the bands in VIS and NIR domains, rely on the pigments (e.g., chlorophyll, carotene and anthocyanin, etc.), structure and physiology of tree canopy and have great potential in the prediction of forest structural parameters [48,49]. Particularly, using hyperspectral narrow band metrics can relatively weaken the influences of soil background reflectance, illumination and atmospheric absorption $[17,50]$. The vegetation indices are the most commonly used narrow band metrics in the prediction of forest structural parameters [37,51,52]. The vegetation indices such as the soil-adjusted vegetation index (SAVI), atmospherically resistant vegetation index (ARVI), and normalized difference vegetation index (NDVI) are considered to be correlated with $N, G, V$ and AGB [23,53]. Zhang et al. [54] used HJ-1 hyperspectral data to predict forest AGB in a subtropical forest and found that SAVI is strongly related to the AGB $(r=0.91)$. Nevertheless, in a densely forest area, the hyperspectral data metrics are prone to asymptotically reach a saturation level [55]. Moreover, since the hyperspectral data usually provide horizontal information, it has certain limitations in quantifying the vertical structure of forests [56]. These limitations can influence the accuracy of predictions of forest structural parameters.

An integration of airborne LiDAR and hyperspectral data is expected to provide more information on the prediction of forest structural parameters. However, few studies have attempted to improve forest structural parameters predictions by integrating airborne LiDAR and hyperspectral data. Dalponte et al. [42] integrated airborne discrete point cloud LiDAR and hyperspectral data to predict stem diameter and volume in a temperate forest and found that the improvement in accuracies of stem diameter and volume were $0.4 \%$ and $0.5 \%$, respectively. Luo et al. [57] integrated airborne discrete point cloud LiDAR and hyperspectral data to estimate AGB in a northern temperate deciduous forest. The results indicated that by using integrated discrete point cloud LiDAR and hyperspectral data, $2.2 \%$ more of the variability in AGB was explained. In previous studies, most have only focused on the prediction of forest biomass by integrating discrete-return LiDAR and hyperspectral data in temperate and boreal forests. Since the acquisition modalities and structures of FWF LiDAR and hyperspectral data are disparate, it is difficult to integrate FWF LiDAR and hyperspectral data at the raw data level [58]. The integration commonly includes transforming FWF LiDAR data into two-dimensional images and adding suites of hyperspectral metrics or the information of tree-species derived from hyperspectral data into FWF data [23,32,53].

However, the predictions of forest structural parameters have been mainly implemented in temperate and boreal forests, and there are few published studies from subtropical forest. Moreover, few studies have used radiometrically and geometrically calibrated FWF LiDAR data in analysis, therefore, the synergetic effects of FWF LiDAR and hyperspectral data could be influenced by the target backscattering characteristics and scan geometry. In addition, previous studies did not comprehensively extract and optimize suites of FWF LiDAR and hyperspectral metrics, and the relativities and synergetic effects of point cloud, full-waveform and hyperspectral metrics have not been fully explored in the prediction of forest structural parameters. To the best of our knowledge, no previous study has integrated simultaneously acquired airborne FWF LiDAR and hyperspectral data to predict forest structural parameters in subtropical forests. The objectives of this paper are: (1) to calibrate the airborne FWF LiDAR data by the physical process-driven and voxel-based models; (2) to integrate and assess the synergetic effects of FWF LiDAR and hyperspectral data-derived metrics for predicting forest structural parameters in subtropical forests; and (3) to validate the predictive models fitted by DPC, FW and HS individually, and in combination using field measured data and to analyze the residuals of the prediction. 


\section{Materials and Methods}

Figure 1 shows the workflow for forest structural parameters prediction. First, the FWF LiDAR data and hyperspectral data were preprocessed to extract discrete point cloud data, calibrate the pulse amplitude and waveform shape, and reduce the influences of atmospheric interference and terrain distortion. Second, different suites of FWF LiDAR and hyperspectral metrics, i.e., point cloud (derived from full-waveform) (DPC) metrics and full-waveform (geometric and radiometric features) (FW) metrics and hyperspectral (original reflectance bands, vegetation indices and statistical indices) (HS) metrics, were extracted and selected using correlation analysis and principal component analysis (PCA), and the relativities of selected metrics were assessed using Pearson's correlation analysis. Finally, the selected DPC, FW and HS were used to fit regression models individually, and in combination to predict $\mathrm{DBH}, \mathrm{H}_{\mathrm{L}}, \mathrm{N}, \mathrm{G}, \mathrm{V}$ and $\mathrm{AGB}$, and the capability of the predictive models and synergetic effects of metrics were assessed.

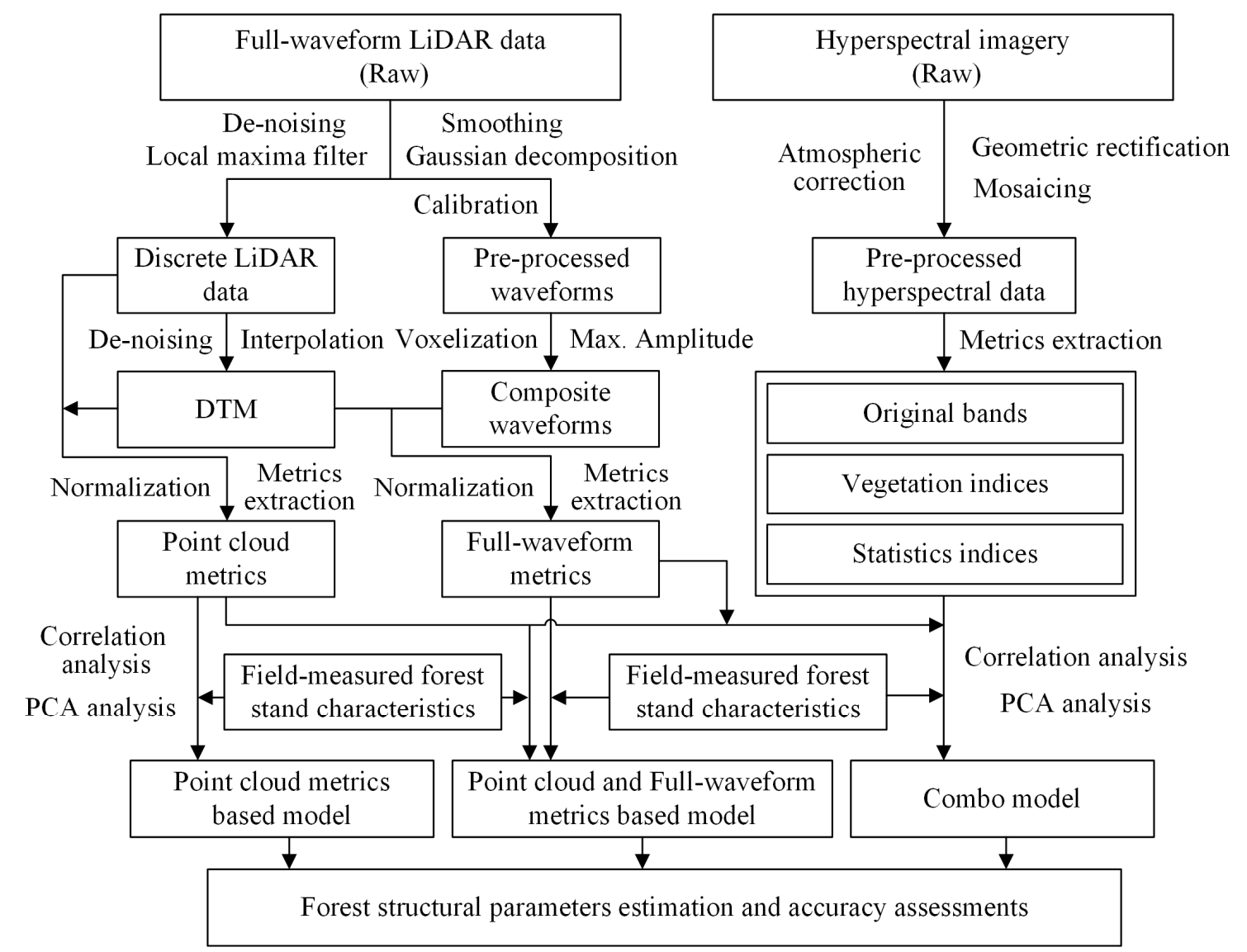

Figure 1. The overview of the workflow for prediction of forest structural parameters using simultaneously acquired airborne full-waveform LiDAR and hyperspectral data in subtropical forests.

\subsection{Study Area}

The nearly 1103 ha study area is located in the Yushan forest $\left(120^{\circ} 42^{\prime} 9.4^{\prime \prime} \mathrm{E}, 31^{\circ} 40^{\prime} 4.1^{\prime \prime} \mathrm{N}\right)$, situated in the southern Jiangsu provinces, southeast China (Figure 2). The annual mean temperature and precipitation are $15.6^{\circ} \mathrm{C}$ and $1062.5 \mathrm{~mm}$, respectively. The elevation of the Yushan forest ranges from 20 to $261 \mathrm{~m}$ above sea-level. The Yushan forest is north subtropical secondary forest and has three types of forests: coniferous tree species dominated, broadleaved tree species dominated and mixed tree species forests [59]. Chinese fir (Cunninghamia lanceolata (Lamb.) Hook.) and Masson pine (Pinus massoniana Lamb.) are the main coniferous tree species. Sweet gum (Liquidambar formosana Hance) and Sawtooth oak (Quercus acutissima Carruth.) are the major broadleaved tree species in the study area. 


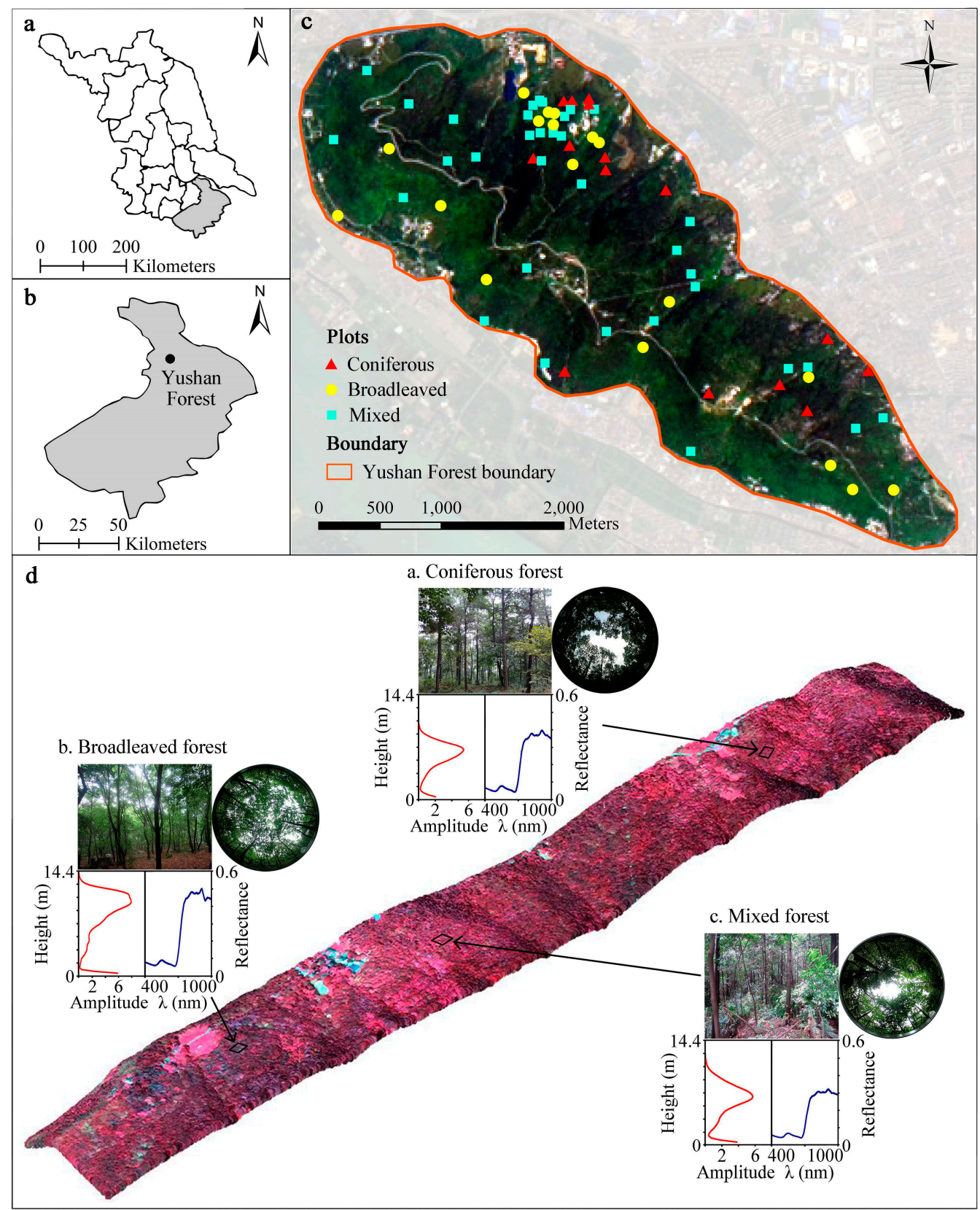

Figure 2. (a,b) Location of the Yushan Forest study site in Suzhou city, Jiangsu province; (c) the remote sensing image of Yushan Forest with a true color composition and the plot distributions of the three forest types; (d) three-dimensional display of a strip of point cloud data (the color of each point is extracted from the hyperspectral image). Picture, hemispherical, composite waveform and spectral reflectance of three typical forest plots are presented along the strip.

\subsection{Field Data}

Field surveys were conducted under leaf-on condition in June and August 2012 and August 2013. Guided by the pre-stratified stand inventory data in 2012, a total of 67 square $\left(30 \times 30 \mathrm{~m}^{2}\right)$ field plots were established. These plots covered multiple site indices, age classes and tree species, which can be classified into three types according to the composition of the tree species: (i) coniferous tree species forest $(n=15)$; (ii) broadleaved tree species forest $(n=18)$; and (iii) mixed tree species forest $(n=34)$.

The coordinates of the plot corners were acquired using Trimble GPS measurements with the result of sub-meter accuracy. All the live trees within each plot, which have a DBH $>5 \mathrm{~cm}$ were measured. The measurement of individual tree parameters can be seen in [41]. The dead wood and 
small trees which has a $\mathrm{DBH}<5 \mathrm{~cm}$ within the plot were also recorded, but excluded in the calculations of biomass and volume. The six plot-level forest structural parameters, including $D B H, H_{L}, N, G$, $\mathrm{V}$ and AGB, were calculated using the measured individual tree data. Species-specific allometric equations and general volume equations of local or nearby provinces were used to calculate AGB and $\mathrm{V}$, respectively (Tables A1 and A2). Within each plot, the AGB and V of each individual tree were calculated according to the DBH and $\mathrm{H}$ measured in the field, and then summed to the plot-level AGB and V. Table 1 provides a summary of the six forest structural parameters at plot-level.

Table 1. Summary statistics of field-measured forest structural parameters in the study area $(n=67$, size $=900 \mathrm{~m}^{2}$ ).

\begin{tabular}{ccccccc}
\hline \multirow{2}{*}{ Parameters } & \multicolumn{2}{c}{ Coniferous Forests $(\mathbf{n}=\mathbf{1 5})$} & \multicolumn{2}{c}{ Broadleaved Forests $(\mathbf{n}=\mathbf{1 8})$} & \multicolumn{2}{c}{ Mixed Forests $(\mathbf{n}=\mathbf{3 4})$} \\
\cline { 2 - 6 } & Mean & Std. Dev. & Mean & Std. Dev. & Mean & Std. Dev. \\
\hline DBH & 13.92 & 3.09 & 16.90 & 4.01 & 14.33 & 3.16 \\
H $_{\mathrm{L}}$ & 10.41 & 1.84 & 12.25 & 3.00 & 10.60 & 1.57 \\
N & 1692.73 & 619.81 & 986.28 & 441.67 & 1467.59 & 413.82 \\
G & 25.96 & 6.01 & 24.44 & 6.56 & 25.23 & 6.24 \\
V & 124.80 & 24.51 & 142.05 & 34.31 & 126.71 & 26.91 \\
AGB & 77.87 & 23.27 & 98.69 & 47.45 & 88.81 & 30.04 \\
\hline
\end{tabular}

Note: $\mathrm{DBH}=$ diameter at breast height $(\mathrm{cm}) ; \mathrm{H}_{\mathrm{L}}=$ Lorey's mean height $(\mathrm{m}) ; \mathrm{N}=$ stem number $\left(\mathrm{ha}^{-1}\right) ; \mathrm{G}=$ basal area $\left(\mathrm{m}^{2} \cdot \mathrm{ha}^{-1}\right) ; \mathrm{V}=$ volume $\left(\mathrm{m}^{3} \cdot \mathrm{ha}^{-1}\right) ; \mathrm{AGB}=$ above ground biomass $\left(\mathrm{Mg} \cdot \mathrm{ha}^{-1}\right)$. Std. Dev. = standard deviation.

\subsection{Remote Sensing Data}

In August 2013, the airborne full-waveform LiDAR and hyperspectral data were simultaneously obtained using the LiCHy System [60]. The platform was flown at the height of $900 \mathrm{~m}$ above ground and the datasets covered the whole Yushan Forest. Full-waveform LiDAR data were obtained using the Riegl LMS-Q680i scanner. The scanning angle was $\pm 15^{\circ}$ from nadir, and the pulse repetition frequency was $360 \mathrm{kHz}$. The temporal sample spacing for recording returned waveforms was $1 \mathrm{~ns}$ (15 cm in distance approximately), and the size of the footprint at nadir was $0.45 \mathrm{~m}$ in diameter. In the overlapping regions, the pulse density was three times higher than a single strip. Hyperspectral data were acquired using an AISA Eagle II sensor with 64 bands and the spectral resolution was $3.3 \mathrm{~nm}$. The sensor obtained hyperspectral images in the pattern of push-broom imaging and the spectrum ranges covered from $400 \mathrm{~nm}$ to $970 \mathrm{~nm}$. The spatial and radiative resolution of the hyperspectral data were $0.6 \mathrm{~m}$ and $12 \mathrm{bit}$, respectively. The geometric accuracy of each pixel was less than one meter with an inertial measurement unit (IMU), which utilized real-time differential corrections by a 12-channel GPS receiver. Table 2 summarizes the characteristics of the full-waveform LiDAR and hyperspectral sensors.

Table 2. The summary of flight parameters and properties of the full-waveform LiDAR and hyperspectral sensors.

\begin{tabular}{lll}
\hline Parameters & Riegl LMS-Q680i & AISA Eagle II \\
\hline Data of acquisition & 17 August 2013 & 17 August 2013 \\
Flight height & $900 \mathrm{~m}$ & $900 \mathrm{~m}$ \\
Flight speed & $55 \mathrm{~m} / \mathrm{s}$ & $55 \mathrm{~m} / \mathrm{s}$ \\
Beam divergence & $0.5 \mathrm{mrad}$ & - \\
IFOV & - & $0.65 \mathrm{mrad}$ \\
Spatial resolution & $0.45 \mathrm{~m}$ & $0.6 \mathrm{~m}$ \\
Wavelength & $1550 \mathrm{~nm}$ & $400-970 \mathrm{~nm}$ \\
Bands & 1 & 64 \\
Swath width & $1040 \mathrm{~m}$ & $612 \mathrm{~m}$ \\
Bit depth & - & $12 \mathrm{bits}$ \\
Average pulse distance & 0.49 & - \\
Average point density & 8.37 & - \\
\hline
\end{tabular}




\subsection{Remote Sensing Data Pre-Processing}

\subsubsection{Full-Waveform LiDAR Data Pre-Processing}

First, a de-noising algorithm and a Gaussian filter were applied to suppress and smooth the background noise of each returned waveform. The full width at half-maximum (FWHM) was used to calculate the kernel size of Gaussian filter [61]. Then, the locations and amplitudes of each peak within the waveform were extracted using a local maxima peak detection filter [62]. Finally, the returned waveform was decomposed using the Gaussian decomposed algorithm.

The LiDAR point clouds can be derived from the FWF LiDAR data using the Gaussian decomposed algorithm. Generally, the following equation can be used to decompose the backscattered waveform into Gaussian components:

$$
f(x)=b+\sum_{i=1}^{n} a_{i} e^{-\left(x-t_{i}\right)^{2} / 2 \sigma_{i}^{2}}
$$

where $f(x)$ stands for the returned waveform, $b$ represents the background noise, and $n$ is the number of decomposed Gaussian components. The $a_{i}, t_{i}$ and $\sigma_{i}$ are the parameters corresponding to pulse amplitude, time of round trip, and the pulse width, respectively [31]. Then, the Levenberg-Marquardt algorithm and a nonlinear least squares method were applied to fit multiple Gaussian components into the backscattered waveform. The LiDAR point clouds extracted from FWF LiDAR data were stored as the format of LAS 1.3 and used for analysis.

In this study, the points in the ground and upper surface of the forest canopy were applied to create the digital terrain model (DTM) and digital surface model (DSM), respectively. The cell size of DTM and DSM was $0.6 \mathrm{~m}$, the same as the resolution of the hyperspectral data. The value in each cell was calculated as the mean elevation of these points, and the cells which had no points were interpolated using neighboring cells by a linear interpolation approach. The value of the DTM was subtracted from each point elevation to calculate the normalized point cloud of whole study area.

The returned pulse width $\left(W_{i}{ }^{\Gamma}\right.$, the standard deviation of pulse) and amplitude $\left(I_{i}{ }^{\Gamma}\right.$, the integral of returned waveform, which represent the pulse energy) were derived from Gaussian components [63]. In this study, the pulse width $\left(W_{i}{ }^{\Gamma}\right)$ and amplitude $\left(I_{i}{ }^{\Gamma}\right)$ were calibrated using a physical process-driven approach [31]. The values of the pulse width $\left(W^{e}\right)$ and amplitude $\left(I^{e}\right)$ of the scanner emitted pulses were used to calibrate $W_{i}^{\Gamma}$ and $I_{i}^{\Gamma}$, and the $I_{i}^{\Gamma}$ was corrected for the loss of signal using the distance between the sensor and the object $\left(D_{i}\right)$ and the normalization distance of $D_{o}$ [30]:

$$
\begin{gathered}
W_{i}^{c}=\frac{W_{i}^{\Gamma}}{W^{e}} \\
I_{i}^{c}=\frac{I_{i}^{\Gamma}}{I^{e}} \times\left(\frac{D_{i}}{D_{o}}\right)^{k}
\end{gathered}
$$

where $W_{i}^{c}$ and $I_{i}^{c}$ is the calibrated pulse width and amplitude, respectively. The value of $k$ which depended on the attenuation of signal occur in the atmosphere was set to 2 [30], and the $D_{o}$ was set to $900 \mathrm{~m}$ (the mean height of the platform).

It has been demonstrated in previous studies that the waveform is stretched by the increase in the off-nadir angle [64,65]. Moreover, due to the obtained airborne FWF LiDAR data are normally comprised of multiple overlapping strips, the waveforms in a specific location may come from several strips $[66,67]$. In this study, a voxel-based approach to composite waveforms was used to correct FWF data to avoid the influences of off-nadir angle in the waveform shape and to integrate non-vertical waveforms from multiple strips into composited vertical waveforms. This approach first decomposed the forest canopies into voxels by vertical space partition $\left(0.6 \times 0.6 \times 0.3 \mathrm{~m}^{3}\right)$, and then synthesized raw waveforms from multiple strips into composite vertical waveforms using the maximum amplitude 
value in each voxel (Figure 3). Each composite vertical waveform was normalized using the digital terrain model (DTM).

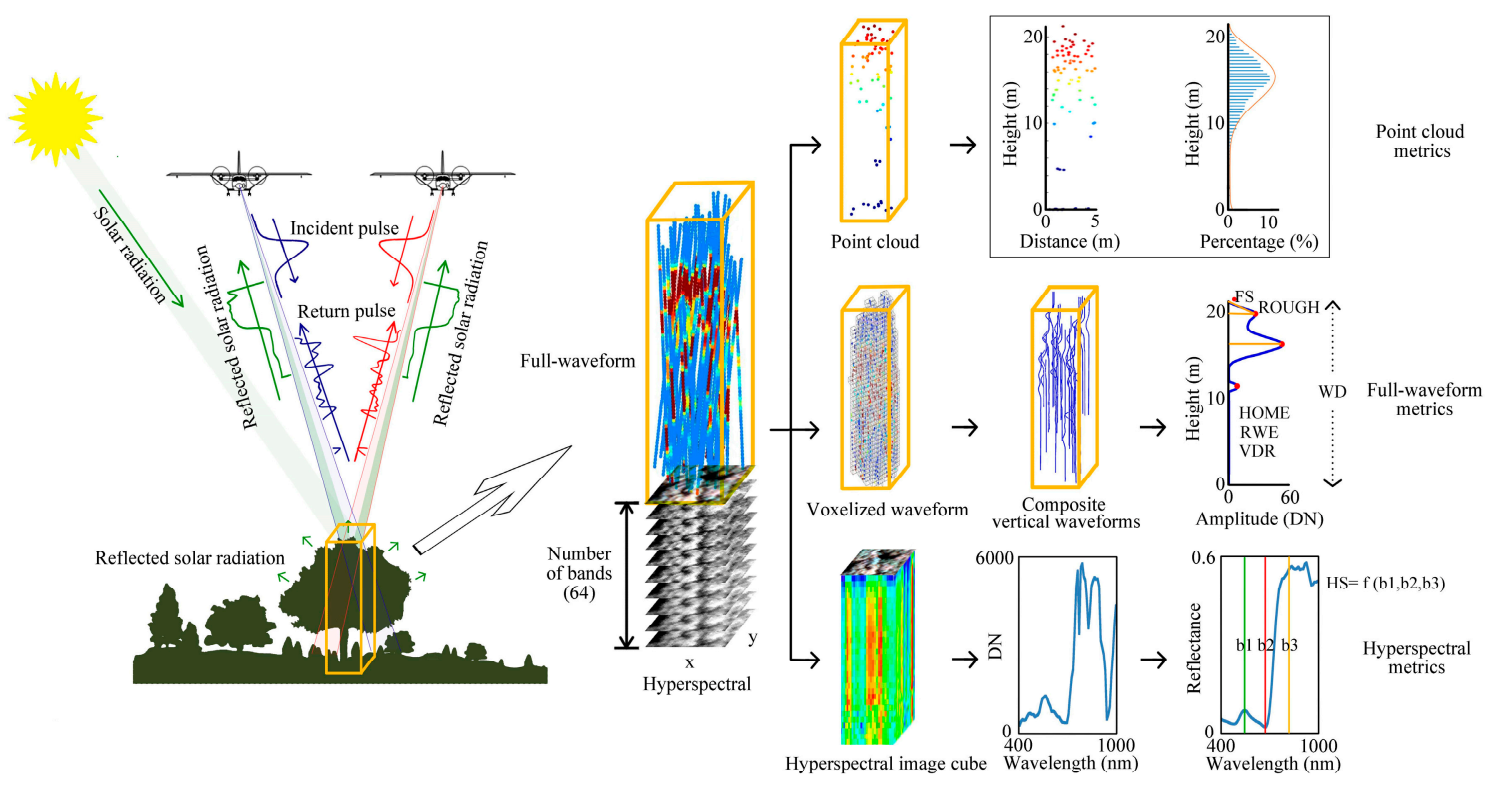

Figure 3. The framework of integration of simultaneously acquired airborne full-waveform (FWF) LiDAR and hyperspectral data (including the processes of data acquisition, datasets integration and metrics extraction). $\mathrm{DN}=$ Digital Number.

\subsubsection{Hyperspectral Data Pre-Processing}

The radiance hyperspectral images covering the whole Yushan forest were geometrically rectified with Global Navigation Satellite System (GNSS) and Inertial Navigation System (INS) data. Then, the geometric-rectified images were mosaicked into a single scene. Atmospheric correction was applied using an empirical line model, combined with field-measured reflectance spectra of different target objects obtained by ASD FieldSpec spectrometer, to get the surface reflectance of covers. In this study, the FWF LiDAR and hyperspectral data were integrated at feature level based on a common coordinate frame. The framework of integration usage of these two datasets can be seen in Figure 3. In order to have the best possible geographical matches between the FWF LiDAR and hyperspectral data, the hyperspectral data were co-registered to the digital surface model (DSM) which calculated from FWF LiDAR data. In the area of each plot, more than 30 ground control points (GCPs) were used on the hyperspectral image $\left(30 \times 30 \mathrm{~m}^{2}\right)$. The root mean square error of co-registration was lower than $0.3 \mathrm{~m}$ (half of one pixel).

\subsection{Full-Waveform LiDAR Metrics}

\subsubsection{Point Cloud Metrics}

The metrics derived from the height normalized LiDAR point cloud were applied to describe the canopy structure of the plots. In this study, the calculated point cloud metrics (DPC) were: (i) the selected height measures $(\mathrm{n}=11)$; (ii) the Weibull parameters fitted to the profile of apparent foliage density $(n=2)$; and (iii) the crown volume zones $(n=4)$. A summary of the point cloud metrics and their descriptions is given in Table 3.

To exclude the influences of below-canopy and non-canopy returns, the point cloud metrics such as percentile heights and canopy return densities were calculated using the points that were two meters 
above ground [68]. The parameters $\alpha$ and $\beta$ of the Weibull curve were extracted from the profile of apparent foliage density as follows [22]:

$$
L(z)=1-\left[e^{-\left(\frac{1-z / H}{\alpha}\right)^{\beta}}\right]
$$

where $\alpha$ and $\beta$ are the parameters of Weibull, $z$ is the height and $H$ is the maximum canopy height in a plot.

The zones of crown volume model (i.e., $\mathrm{O}_{g}, \mathrm{C}_{\mathrm{g}}, \mathrm{E}$ and $\mathrm{O}$ ) were used to characterize the forest crown volume and spatial arrangement of the canopy materials in three-dimensions [69]. First, the forest canopy was decomposed into a matrix of voxels, the size of each voxel was $0.6 \times 0.6 \times 0.3 \mathrm{~m}^{3}$. Second, the voxels within the matrix were classified into "filled" if there was energy returned from the voxel and classified into "empty" if there was no energy returned from the voxel. Third, the "filled" voxels were classified as "euphotic" and "oligophotic" depending on whether the voxel was above or below the threshold height of the uppermost $65 \%$ for all "filled" voxels. Finally, the "empty" voxels were classified into "open" and "closed" gap zones depending on whether they were located above or below the filled voxels.

Table 3. The summary of the FWF LiDAR metrics (i.e., DPC and FW) extracted from FWF LiDAR data (the code and description of each metric are listed).

\begin{tabular}{|c|c|}
\hline FWF LiDAR Metrics & Description \\
\hline \multicolumn{2}{|l|}{ a Point cloud metrics (DPC) } \\
\hline Percentile heights $\left(h_{25}, h_{50}, h_{75}\right.$ and $\left.h_{95}\right)$ & $\begin{array}{l}\text { The percentiles of the canopy height distributions (25th, 50th, 75th } \\
\text { and 95th). }\end{array}$ \\
\hline $\begin{array}{l}\text { Canopy return density }\left(d_{1}, d_{3}, d_{5}, d_{7}\right. \\
\left.\text { and } d_{9}\right)\end{array}$ & $\begin{array}{l}\text { The proportion of points above the height percentiles (10th, 30th, } \\
50 \text { th, 70th and 90th). }\end{array}$ \\
\hline Coefficient of variation of heights $\left(\mathrm{h}_{\mathrm{cv}}\right)$ & Coefficient of variation of heights of all points. \\
\hline Canopy cover above $2 \mathrm{~m}$ (Cover) & Percentage of all points above $2 \mathrm{~m}$. \\
\hline $\begin{array}{l}\alpha \text { and } \beta \text { parameter of Weibull } \\
\text { distribution (i.e., } W_{\alpha} \text { and } W_{\beta} \text { ) }\end{array}$ & $\begin{array}{l}\text { The } \alpha \text { and } \beta \text { parameters of the Weibull distribution fitted to foliage } \\
\text { density profile. }\end{array}$ \\
\hline $\begin{array}{l}\text { Open and Closed gap zones of canopy } \\
\text { volume models }(\mathrm{CVM})\left(\text { i.e., } \mathrm{O}_{\mathrm{g}} \text { and } \mathrm{C}_{\mathrm{g}} \text { ) }\right.\end{array}$ & $\begin{array}{l}\text { The empty voxels located above and below the canopy } \\
\text { respectively. }\end{array}$ \\
\hline $\begin{array}{l}\text { Euphotic and Oligophotic zones of CVM } \\
\text { (i.e., E and O) }\end{array}$ & $\begin{array}{l}\text { The voxels located within an uppermost percentile }(65 \%) \text { of all } \\
\text { filled grid cells of that column, and voxels located below the point } \\
\text { in the profile. }\end{array}$ \\
\hline \multicolumn{2}{|l|}{ b Full-waveform metrics (FW) } \\
\hline Height of median energy (HOME) & The distance from waveform centroid to the ground. \\
\hline Waveform distance (WD) & The distances from waveform beginning to the ground. \\
\hline Vertical distribution ratio (VDR) & The differences between the WD and the HOME, divided by WD. \\
\hline Number of peaks (NP) & $\begin{array}{l}\text { The number of detected peaks within each normalized } \\
\text { composite waveform. }\end{array}$ \\
\hline $\begin{array}{l}\text { Roughness of outermost canopy } \\
\text { (ROUGH) }\end{array}$ & The distance from the waveform beginning to the first peak. \\
\hline Front slope angle (FS) & $\begin{array}{l}\text { The vertical angles from waveform beginning to the first peak of } \\
\text { canopy return energies. }\end{array}$ \\
\hline Return waveform energy (RWE) & $\begin{array}{l}\text { The total received energy, i.e., the area below the waveform } \\
\text { between beginning and end. }\end{array}$ \\
\hline Intensity of Gaussian component (Int) & $\begin{array}{l}\text { Mean of the intensity of Gaussian components within } \\
\text { one waveform. }\end{array}$ \\
\hline Full width at half maximum (FWHM) & Full width at half maximum of one waveform. \\
\hline
\end{tabular}

Note: ${ }^{a}$ These DPC were calculated using point cloud derived from FWF LiDAR data; ${ }^{\mathrm{b}}$ The FW were extracted from the waveforms which were pre-processed and calibrated. See text for details. 


\subsubsection{Full-Waveform Metrics}

Full-waveform metrics (FW) provide three-dimensional forest structure information by extracting radiometric and geometric properties of recorded backscattered waveforms. In this study, 18 full-waveform metrics including the mean $(\mu)$ and standard deviation $(\sigma)$ within each plot were extracted from composite waveforms (Figure 3). First, the full-waveform metrics (Table 3) of each composite waveform were calculated; second, the mean and standard deviation of all the full-waveform metrics in each plot were calculated as the full-waveform metrics at plot-level. Table 3 gives the summary of these full-waveform metrics and descriptions.

\subsection{Hyperspectral Metrics}

The hyperspectral metrics (HS) are good indices in the prediction of forest structural properties, due to their ability to describe crown structures, which are related to vegetation pigments, physiology and stress, directly or indirectly. In this study, 112 hyperspectral metrics were derived from the preprocessed hyperspectral image, including: (i) reflectance values from AISA Eagle II channels; (ii) vegetation indices; (iii) first 10 components of the principal component transformation (PCT), independent components transformation (ICT) and minimum noise fraction transformation (MNF).

The spectral reflectance was strongly correlated with the structural properties (e.g., leaf area index, the amount of biomass and spatial arrangement of structures) of forests [70]. In this study, all channels in the domains of VIS, RE, and NIR were used. The mean values of $50 \times 50$ pixels within the plots were calculated from the reflectance of the entire 64 channels. The same procedure for calculation was followed to extract the other hyperspectral metrics (vegetation indices and first 10 components of PCT, ICT and MNF).

Hyperspectral vegetation indices, which rely on specific absorption features, are the most commonly used narrow band metrics. The vegetation indices calculated from the hyperspectral image have great advantages in predicting forest structural parameters [23,49]. In this study, 18 vegetation indices were extracted and summarized in Table 4.

Table 4. A summary of the vegetation indices with respective equations and references. Wavelengths chosen were the closest AISA wavelengths to the equations in the cited literature.

\begin{tabular}{lcc}
\hline Vegetation Index & Equation & Reference \\
\hline Simple ratio (SR) & $\rho 801 / \rho 676$ & {$[71]$} \\
Normalized difference vegetation index & $(\rho 801-\rho 676) /(\rho 801+\rho 676)$ & {$[72]$} \\
(NDVI) & $2.5 \times[(\rho 801-\rho 676) /(1+\rho 801+6 \times \rho 676-7.5 \times \rho 479)]$ & {$[73]$} \\
Enhanced vegetation index (EVI) & $(\rho 801-\rho 553) /(\rho 801+\rho 553)$ & {$[74]$} \\
Green normalized difference vegetation & $1.5 \times(\rho 801-\rho 676) /(\rho 801+\rho 676+0.5)$ & {$[75]$} \\
index (GNDVI) & {$[\rho 801-(2 \times \rho 676-\rho 479)] /[\rho 801+(2 \times \rho 676-\rho 479)]$} & {$[76]$} \\
Soil adjusted vegetation index (SAVI) & {$[(\rho 724+\rho 753) / 2]-\rho 733$} & {$[77]$} \\
Atmospherically resistant vegetation & $(\rho 676-\rho 498) / \rho 753$ & {$[78]$} \\
index (ARVI) & $\rho 743 / \rho 724$ & {$[79]$} \\
Red-edge vegetation stress index (RVSI) & $(\rho 733-\rho 743) /(\rho 714-\rho 724)$ & {$[80]$} \\
Plant senescence reflectance index (PSRI) & $R E D / G R E E N$ & {$[81]$} \\
Vogelmann red edge index 1 (VOG1) & $(\rho 534-\rho 572) /(\rho 534+\rho 572)$ & {$[82]$} \\
Vogelmann red edge index 2 (VOG2) & $\rho 534 / \rho 572$ & {$[83]$} \\
Red green ratio index (RGRI) & $\rho 898 / \rho 975$ & {$[84]$} \\
Photochemical reflectance index (PRI) & $(1 / \rho 507)-(1 / \rho 553)$ & {$[84]$} \\
Photochemical reflectance ratio (PRR) & $(1 / \rho 507)-(1 / \rho 705)$ & {$[85]$} \\
Water band index (WBI) & $(1 / \rho 553)-(1 / \rho 705)$ & {$[85]$} \\
Carotenoid reflectance index 1 (CRI) & $\rho 801 \times[(1 / \rho 553)-(1 / \rho 705)]$ & \\
Carotenoid reflectance index 2 (CRI) & & \\
Anthocyanin reflectance index 1 (ARI1) & & \\
Anthocyanin reflectance index 2 (ARI2) & & \\
\hline
\end{tabular}

The principal component analysis (PCA), minimum noise fraction analysis (MNF) and independent components analysis (ICA) are three algorithms which are commonly used to de-noise and extract primary information from hyperspectral images. We used these three approaches to 
calculate 192 components (64 components for each approach), out of which we used the first 10 of each approach for analysis, to explore whether there was a component that summarized the forest structural parameters-related channels to one value, and therefore, to ensure the models' conciseness $[48,86]$.

\subsection{Metrics Optimization and Regression Analysis}

Previous studies have demonstrated that optimization of the candidate metrics can reduce irrelevant and redundant information and help create highly efficient, transferable and robust productive models. In this study, all of the FWF LiDAR and hyperspectral metrics were first optimized using correlation analysis. The 15 metrics, which had relatively high correlation with the forest structural parameters, were correspondingly selected from point cloud metrics (DPC), full-waveform metrics (FW) and hyperspectral metrics (HS). Then, the 45 metrics (15 point cloud, 15 full-waveform and 15 hyperspectral metrics) were analyzed using the biplot of PCA, which can be used to select the important metrics in the clusters [87]. The 12 point cloud, 8 full-waveform and 10 hyperspectral metrics which highly correlated with the first and second principal component $(r>0.7)$ and were selected from the three groups divided by the PCA. Finally, the five metrics that had the highest correlations with the first and second principal component in each group were selected as the best metrics to fit the combo models.

The backward stepwise regression approach was applied to relate FWF LiDAR and hyperspectral metrics to field-measured forest structural parameters. In the models, three predictor variables at the $5 \%$ significance level were selected. To ensure the metrics in the models had no serious collinearity, the models which had the condition number $(k)<30$ were selected. Finally, according to the value of the Akaike information criterion (AIC), the best fitting models with the lowest AIC were selected.

In the study, three types of predictive models of $\mathrm{DBH}, \mathrm{H}_{\mathrm{L}}, \mathrm{N}, \mathrm{G}, \mathrm{V}$ and $\mathrm{AGB}$ were developed using DPC, FW, HS and an integration of two or three of these for the combo models. First, the DPC models (DPC based models) were fitted using 12 DPC alone to predict the six forest structural parameters; second, the FW models (DPC and FW based models) were fitted using the integration of 12 DPC and $8 \mathrm{FW}$ to predict the six forest structural parameters; third, the combo models were fitted using the integration of the best metrics (each of the five metrics selected from PCA groups) to predict the six forest structural parameters. All of the models were assessed by adjusted coefficient of determination $\left(\operatorname{Adj}-R^{2}\right)$, Root-Mean-Square-Error (RMSE), and relative RMSE ( $r$ RMSE). The leave-one-out (LOO) cross validation was applied to assess the accuracy of prediction models and assess the synergetic effects of FWF LiDAR and hyperspectral metrics.

\section{Results}

\subsection{Full-Waveform LiDAR and Hyperspectral Metrics Extraction}

All of the metrics, including the point cloud metrics $(n=17)$, full-waveform metrics $(n=18)$ and hyperspectral metrics $(n=112)$ were extracted from the LiDAR point cloud (with height normalized), composite waveform and preprocessed hyperspectral image, respectively. Figure 4 shows the profiles of point cloud and apparent foliage (I), profiles of intensity of energy and composite waveform (II), and the spectral reflectance from $400 \mathrm{~nm}$ to $1000 \mathrm{~nm}$ (III). The profiles of apparent foliage and Weibull distribution appropriately describe the vertical distribution of point cloud. The peak of the Weibull distribution curve in broadleaved forest plot is relatively higher (height $=8.55 \mathrm{~m}$ ), followed by the mixed forest plot (height $=6.34 \mathrm{~m}$ ), and the peak of the Weibull distribution curve in coniferous plots is relatively lower (height $=5.41 \mathrm{~m}$ ). The profiles of composite waveform truly describe the space distribution of energy, and the height of peaks of composite waveform are same as the height of energy concentration. The profiles of intensity of energy and composite waveform are similar to the profiles of point cloud and Weibull distribution, respectively. The spectral reflectance describes the biophysical and biochemical properties of the canopy. The spectral reflectance in the broadleaved 
forest plot is highest (mean $=0.06-0.52$ ), followed by spectral reflectance in the coniferous forest plot (mean $=0.06-0.41)$, and spectral reflectance in the mixed forest plot is lowest (mean $=0.05-0.33$ ).
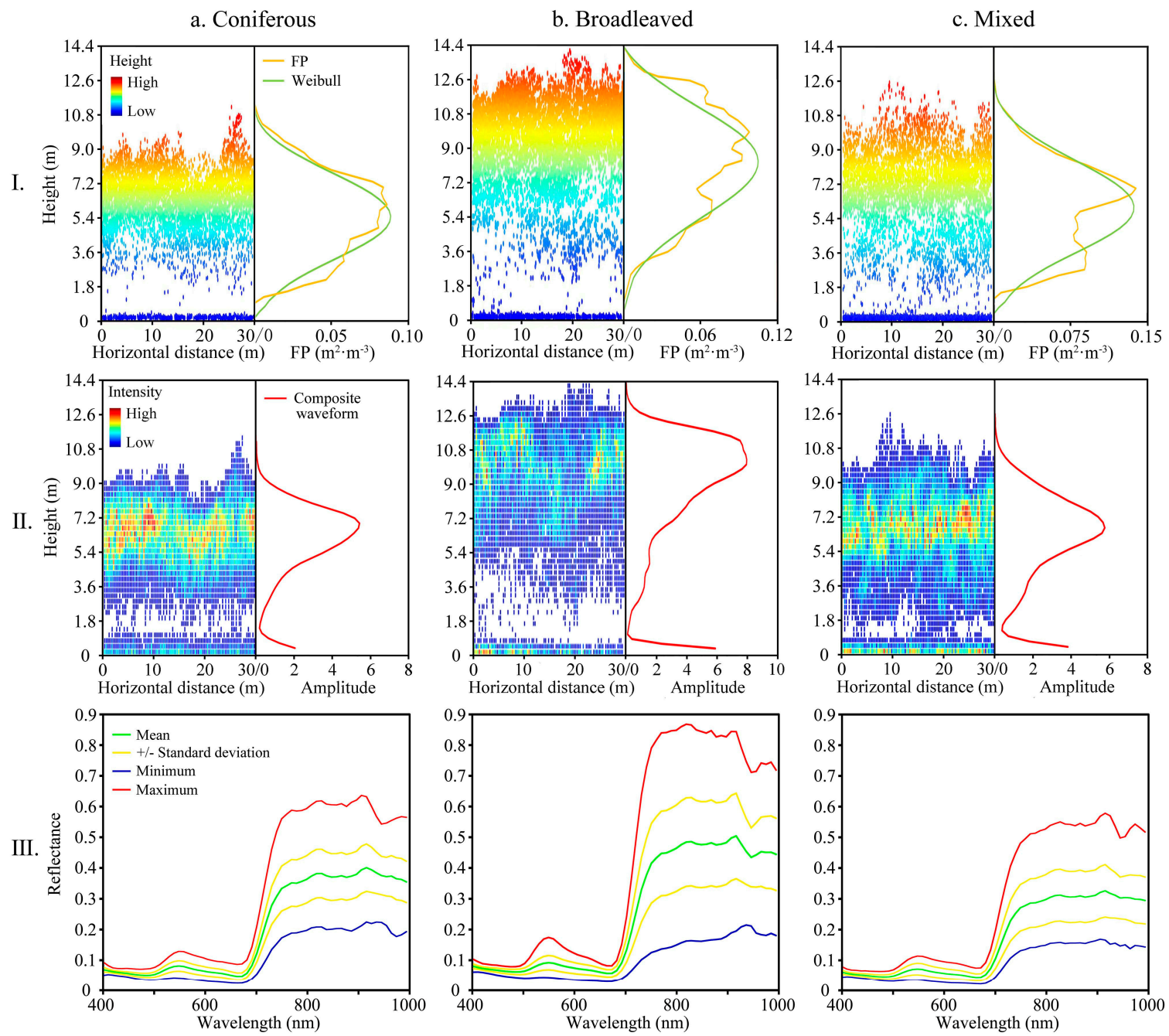

Figure 4. LiDAR point cloud profiles (I left), apparent foliage profiles (FP) (I right), Weibull distributions (I right), intensity of energy profile (II left), composite waveform (II right), and spectral reflectance (III) derived from the plots of coniferous forest (column 1), broadleaved forest (column 2) and mixed forest (column 3).

\subsection{Metrics Selection and Optimization}

Figure 5 shows the projection of the first two PCA scores from the selected point cloud $(n=15)$, full-waveform $(n=15)$ and hyperspectral $(n=15)$ metrics. The first (PCA1) and second (PCA2) components of PCA account for $57.61 \%$ and $31.02 \%$ of the total variance, respectively. In the four groups divided by PCA, 37 metrics in three groups were highly correlated with the PCA1 and PCA2. The 12 point cloud $\left(h_{25}, h_{50}, h_{75}, h_{95}, d_{1}, d_{5}, d_{9}, h_{c v}\right.$, Cover, $\left.W_{\alpha}, E, O\right), 8$ full-waveform $\left(\operatorname{HOME}_{\mu}\right.$, $\mathrm{WD}_{\mu}, \mathrm{VDR}_{\mu}, \mathrm{NP}_{\mu}, \mathrm{RWE}_{\mu}, \mathrm{Int}_{\mu}, \mathrm{HOME}_{\sigma}, \mathrm{WD}_{\sigma}$ ) and 10 hyperspectral (B45, B63, VOG1, NDVI, RVSI, EVI, ARVI, CRI1, PCA1, PCA2) metrics were correlated with the PCA1 and PCA2 higher than 0.7. Most of the point cloud and full-waveform metrics were in the opposite direction. Moreover, most of hyperspectral metrics and FWF LiDAR metrics (point cloud and full-waveform metrics) were orthonormal. Therefore, the FWF LiDAR metrics and hyperspectral metrics could be used as complementary metrics in forest structural parameters prediction. 


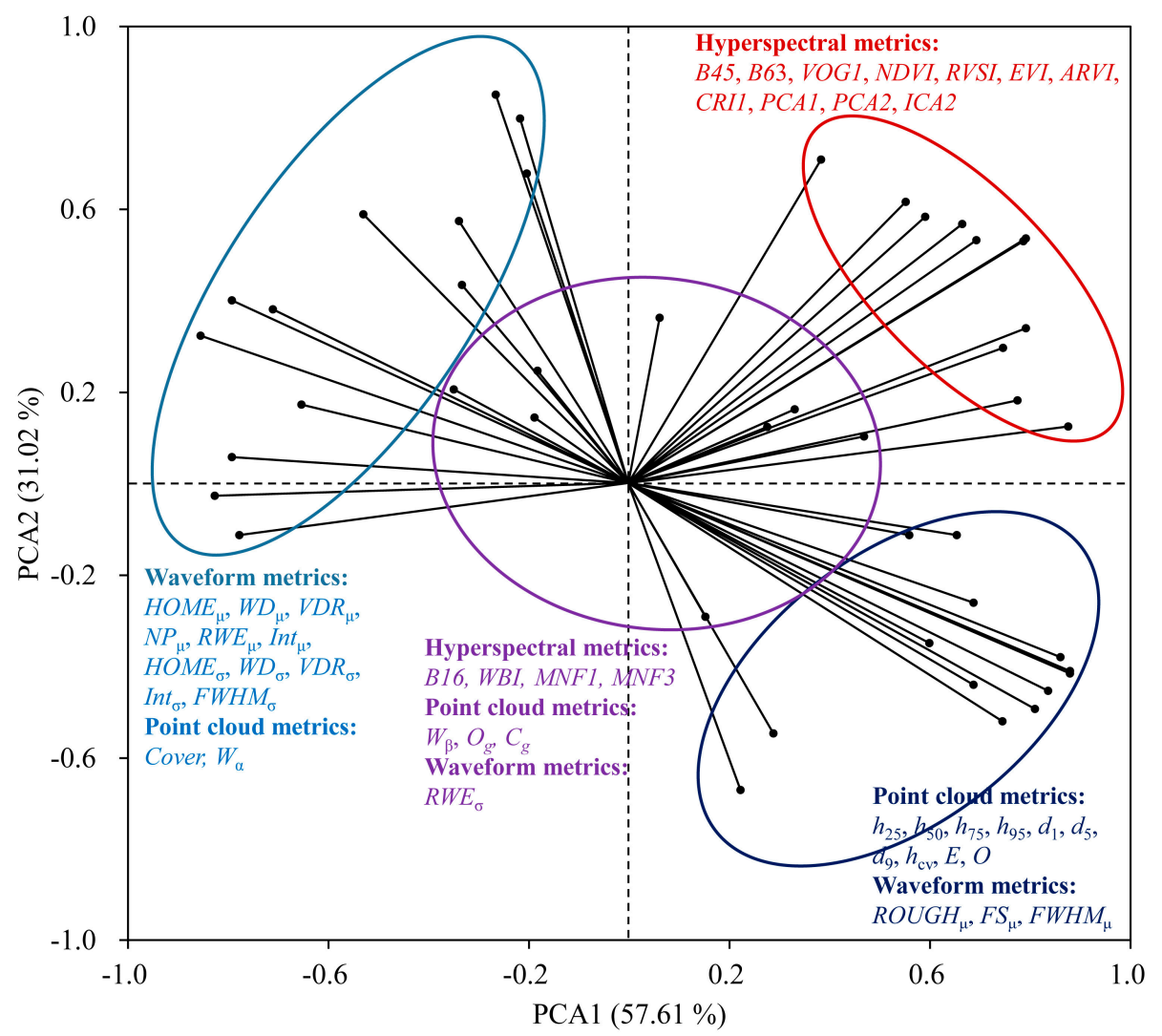

Figure 5. Projection of the first two PCA scores from the selected point cloud, waveform and hyperspectral metrics. The color ellipsoids represent the visual metrics clusters. See Tables 3 and 4 for the description of the metrics.

The five point cloud metrics $\left(h_{50}, h_{75}, d_{1}, E, O\right)$, five full-waveform metrics $\left(\operatorname{HOME}_{\mu}, V R_{\mu}, N_{\mu}\right.$, $\mathrm{RWE}_{\mu}$, and $\mathrm{WD}_{\sigma}$ ) and five hyperspectral metrics (NDVI, RVSI, ARVI, CRI1 and PCA2), which had the highest correlation with PCA1 and PCA2 in each group are shown in Figure 6. According to the result of the correlation analysis, most of the metrics had weak relationships with each other $(r<0.7)$ (Figure 6). Therefore, the metrics in the combo models were non-collinear and the combo models were robust. The hyperspectral metrics of CRI1 and PCA2 had the weakest relationships with the other metrics. However, the metrics related to crown height were relatively strongly correlated with each other $\left(\mathrm{h}_{50}, \mathrm{~h}_{75}\right.$ and $\left.\mathrm{HOME}_{\mu}\right)$ and the waveform metric $\mathrm{HOME}_{\mu}$ had a relatively strong positive correlation with the hyperspectral metrics of RVSI. 


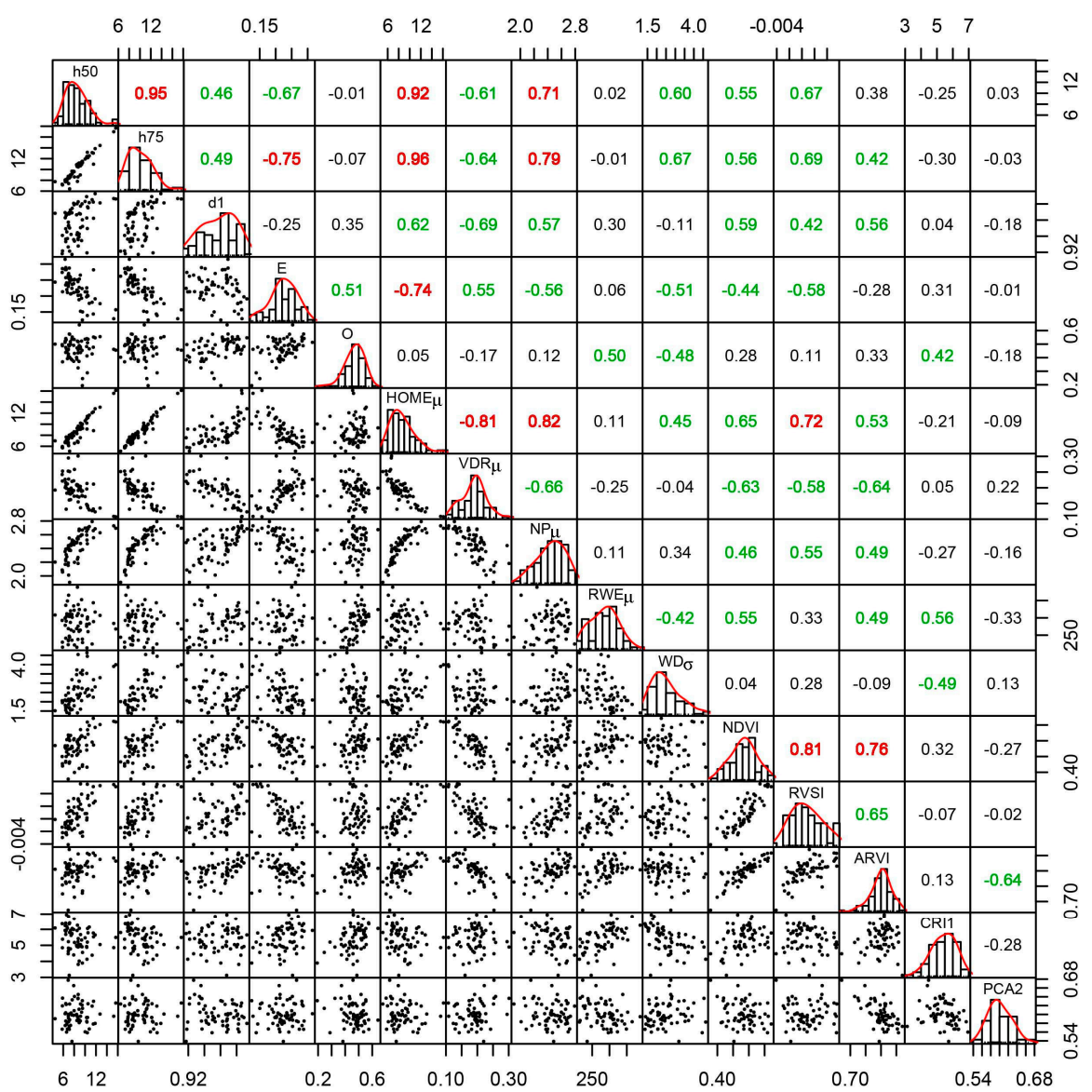

Figure 6. The matrix of the Pearson correlation coefficient ( $r$ ) (upper panel) and scatter plots (lower panel) for the metrics in the combo models. The histograms and distributions are shown in the diagonal line. The red color represents a high degree of correlation $(r>0.7)$, and the green color represents a medium degree of correlation $(0.4<r<0.7)$. See Tables 3 and 4 for the description of metrics.

\subsection{Predictive Models with Point Cloud Derived Metrics}

The DPC models obtained using point cloud derived metrics are summarized in Table 5 . The point cloud metrics performed well with models significant at $p<0.01$. All of the forest structural parameters were well predicted, and the accuracies of the predictive models ranged from 0.52 $\left(\right.$ Adj- $R^{2}, r$ RMSE $\left.=40.87 \%\right)$ to $0.81\left(\right.$ Adj- $R^{2}, r$ RMSE $\left.=15.70 \%\right)$. The Lorey's mean height model had the highest accuracy (Adj- $R^{2}=0.81, r$ RMSE $=15.70 \%$ ), followed by the volume model (Adj- $R^{2}=0.69$, $r$ RMSE $=25.76 \%$, the above ground biomass model $\left(\right.$ Adj $-R^{2}=0.68, r$ RMSE $\left.=25.22 \%\right)$, the stem number model (Adj- $R^{2}=0.63, r$ RMSE $=30.63 \%$ ) and the DBH model $\left(\right.$ Adj- $R^{2}=0.54, r$ RMSE $=37.02 \%$ ). The basal area model had the lowest accuracy $\left(\right.$ Adj $-R^{2}=0.52, r$ RMSE $\left.=40.87 \%\right)$.

Table 5. Summary of the forest structural parameters prediction models with point cloud data based metrics and plot-level accuracy assessment results.

\begin{tabular}{clcccc}
\hline Dependent & \multicolumn{1}{c}{ Final Models } & ${ }^{a}$ Adj- $\boldsymbol{R}^{2}$ & RMSE & rRMSE (\%) & $\boldsymbol{k}$ \\
\hline $\mathrm{DBH}$ & $18.527+0.644 \mathrm{~h}_{25}-1.402 \mathrm{~W}_{\alpha}-33.340 \mathrm{E}$ & $0.54^{* *}$ & 5.53 & 37.02 & 17.00 \\
$\mathrm{H}_{\mathrm{L}}$ & $1.441+0.901 \mathrm{~h}_{50}+8.703 \mathrm{~d}_{9}+3.206 \mathrm{~W}_{\alpha}$ & $0.81^{* *}$ & 1.73 & 15.70 & 11.26 \\
$\mathrm{~N}$ & $-4699.282-71.688 \mathrm{~h}_{50}+5796.245$ Cover $+4437.070 \mathrm{E}$ & $0.63^{* *}$ & 425.41 & 30.63 & 15.77 \\
$\mathrm{G}$ & $-44.816+68.045 \mathrm{~d}_{1}-4.286 \mathrm{~d}_{5}+12.927 \mathrm{O}$ & $0.52^{* *}$ & 10.29 & 40.87 & 13.90 \\
$\mathrm{~V}$ & $-105.911+10.211 \mathrm{~h}_{50}+166.787 \mathrm{~d}_{1}-229.444 \mathrm{~d}_{9}$ & $0.69^{* *}$ & 33.59 & 25.76 & 10.52 \\
$\mathrm{AGB}$ & $-181.605+8.059 \mathrm{~h}_{95}+237.778 \mathrm{~d}_{1}-158.626 \mathrm{~h}_{\mathrm{cv}}$ & $0.68^{* *}$ & 22.45 & 25.22 & 9.53 \\
\hline
\end{tabular}

Note: See Tables 1 and 3 for code of forest structural parameters and point cloud metrics, respectively. ${ }^{\text {a }}$ Level of significance: ${ }^{* *} p<0.01$. 


\subsection{Predictive Models with Full-Waveform LiDAR Metrics}

The FW models obtained using FWF LiDAR metrics are summarized in Table 6. The FWF LiDAR metrics performed well with models significant at $p<0.01$. All of the forest structural parameters were well predicted, and the accuracies of predictive models ranged from 0.62 (Adj- $R^{2}, r$ RMSE $=25.24 \%$ ) to $0.87\left(\right.$ Adj- $R^{2}, r$ RMSE $\left.=11.01 \%\right)$. The Lorey's mean height model had the highest accuracy (Adj- $R^{2}=0.87$, $r$ RMSE $=11.01 \%)$, followed by the above ground biomass model (Adj- $R^{2}=0.82, r$ RMSE $\left.=15.41 \%\right)$, volume model (Adj- $R^{2}=0.80, r$ RMSE $\left.=17.32 \%\right)$, stem number model $\left(\right.$ Adj- $R^{2}=0.70, r$ RMSE $\left.=21.92 \%\right)$ and basal area model (Adj- $R^{2}=0.64, r$ RMSE $=31.30 \%$ ); the DBH model had the lowest accuracy $\left(\right.$ Adj- $R^{2}=0.62, r$ RMSE $\left.=25.24 \%\right)$. Compared with the models only using DPC, the improvement in models using DPC and FW were significant. The improvements in accuracy ranged from 0.06 to 0.14 $\left(\triangle \operatorname{Adj}-R^{2}, \Delta r\right.$ RMSE $\left.=4.69-11.78 \%\right)$.

Table 6. Summary of the forest structural parameters prediction models with FWF LiDAR metrics (integration of point cloud based metrics and full-waveform based metrics) and plot-level accuracy assessment results.

\begin{tabular}{|c|c|c|c|c|c|}
\hline Dependent & Final Models & ${ }^{\text {a }} \mathrm{Adj}-R^{2}$ & RMSE & $r$ RMSE (\%) & $k$ \\
\hline DBH & $10.925+1.051 \mathrm{~h}_{25}-31.923 \mathrm{E}+20.846 \mathrm{VDR}_{\mu}$ & $0.62 * *$ & 3.77 & 25.24 & 13.18 \\
\hline $\mathrm{H}_{\mathrm{L}}$ & $2.549+0.408 \mathrm{~h}_{95}+0.431 \mathrm{HOME}_{\mu}-0.007 \mathrm{Int}_{\mu}$ & $0.87^{* *}$ & 1.21 & 11.01 & 19.58 \\
\hline$N$ & $-5313.482+6506.593$ Cover $+4449.668 \mathrm{E}-65.711 \mathrm{WD}_{\mu}$ & $0.70 * *$ & 304.40 & 21.92 & 9.60 \\
\hline G & $-51.975+68.144 \mathrm{~d}_{1}+11.438$ Cover $-0.080 \mathrm{HOME}_{\sigma}$ & $0.64^{* *}$ & 7.88 & 31.30 & 14.84 \\
\hline $\mathrm{V}$ & $-28.826+44.895 \mathrm{~d}_{1}+7.627 \mathrm{HOME}_{\mu}+0.177 \mathrm{RWE}_{\mu}$ & 0.80 ** & 22.58 & 17.32 & 14.64 \\
\hline AGB & $-446.300+12.749 h_{50}+398.166 d_{1}+262.543 V_{D R} R_{\mu}$ & $0.82 * *$ & 13.72 & 15.41 & 15.81 \\
\hline
\end{tabular}

Note: See Tables 1 and 3 for code of forest structural parameters and FWF LiDAR metrics, respectively. ${ }^{\text {a }}$ Level of significance: $* * 0.01$.

\subsection{Predictive Models with Combined Full-Waveform LiDAR and Hyperspectral Metrics}

The combo models obtained using integrated point cloud, full-waveform and hyperspectral derived metrics are summarized in Table 7. The integration of point cloud, full-waveform and hyperspectral metrics performed well with models significant at $p<0.01$. All of the forest structural parameters were well predicted, and the accuracies of the predictive models ranged from 0.68 (Adj- $R^{2}$, $r$ RMSE $=28.67 \%)$ to $0.88\left(\right.$ Adj- $R^{2}, r$ RMSE $\left.=10.68 \%\right)$. The Lorey's mean height model had the highest accuracy (Adj- $R^{2}=0.88, r$ RMSE $=10.68 \%$ ), followed by the above ground biomass model (Adj- $R^{2}=0.84$, $r$ RMSE $=15.14 \%)$, volume model $\left(\right.$ Adj- $R^{2}=0.81, r$ RMSE $\left.=16.37 \%\right)$, stem number model (Adj- $R^{2}=0.72$, $r$ RMSE $=20.16 \%)$ and DBH model $\left(\right.$ Adj- $R^{2}=0.69, r$ RMSE $\left.=23.11 \%\right)$; the basal area model had the lowest accuracy (Adj- $R^{2}=0.68, r$ RMSE $=28.67 \%$ ). Compared with the models only using DPC, the models using integrated DPC, FW and HS significantly improved the accuracies of prediction. The improvements in accuracy ranged from 0.07 to $0.16\left(\Delta \mathrm{Adj}-R^{2}, \Delta r \mathrm{RMSE}=5.02-13.91 \%\right)$. Moreover, compared with the models using FWF LiDAR metrics, the models using integrated DPC, FW and HS slightly improved the accuracies of prediction. The improvements in accuracy ranged from 0.01 to 0.07 $\left(\triangle \mathrm{Adj}-R^{2}, \Delta r \mathrm{RMSE}=0.27-2.63 \%\right)$.

Table 7. Summary of the forest structural parameters prediction models with integrated point cloud, full-waveform and hyperspectral metrics and plot-level accuracy assessment results.

\begin{tabular}{clcccc}
\hline Dependent & \multicolumn{1}{c}{ Final Models } & ${ }^{a}$ Adj- $\boldsymbol{R}^{2}$ & RMSE & rRMSE (\%) & $\boldsymbol{k}$ \\
\hline DBH & $32.009-41.480 \mathrm{VDR}_{\mu}-0.786 \mathrm{NP}_{\mu}-1.454 \mathrm{CRI} 1$ & $0.69^{* *}$ & 3.45 & 23.11 & 6.93 \\
$\mathrm{H}_{\mathrm{L}}$ & $1.549+0.916 \mathrm{~h}_{75}-0.047 \mathrm{WD}_{\sigma}+1.533 \mathrm{NDVI}$ & $0.88^{* *}$ & 1.18 & 10.68 & 6.34 \\
$\mathrm{~N}$ & $-66.329+2940.122 \mathrm{E}+1879.922 \mathrm{O}-90635.301 \mathrm{RVSI}$ & $0.722^{* *}$ & 279.98 & 20.16 & 5.18 \\
$\mathrm{G}$ & $16.252+9.265 \mathrm{NP}_{\mu}+0.050 \mathrm{RWE}_{\mu}-36.932 \mathrm{ARVI}$ & $0.68^{* *}$ & 7.22 & 28.67 & 4.56 \\
$\mathrm{~V}$ & $-168.279+253.243 \mathrm{~d}_{1}+6.371 \mathrm{HOME}_{\mu}-24.130 \mathrm{PCA} 2$ & $0.81^{* *}$ & 21.34 & 16.37 & 5.66 \\
$\mathrm{AGB}$ & $-113.778+11.946 \mathrm{~h}_{50}+58.117 \mathrm{VDR}_{\mu}+124.417 \mathrm{NDVI}$ & $0.84^{* *}$ & 13.48 & 15.14 & 5.59 \\
\hline
\end{tabular}

Note: See Tables 1, 3 and 4 for code of forest structural parameters, FWF LiDAR metrics and hyperspectral metrics, respectively. ${ }^{a}$ Level of significance: ${ }^{* *} p<0.01$. 


\subsection{Assessment of the Predictive Models}

Cross validation of the combo models demonstrated that the relationship between field surveyed and predicted forest structural parameters were close to the 1:1 line (Figure 7). The mean differences between field surveyed and cross-validated models predicted forest structural parameters were not significant statistically (Table 8). The Lorey's mean height model had the highest accuracy $\left(C V-R^{2}=0.85, C V-r R M S E=11.50 \%\right)$, followed by the above ground biomass $\left(C V-R^{2}=0.80\right.$, CV-rRMSE $=17.82 \%)$, volume $\left(C V-R^{2}=0.77, C V-r R M S E=17.95 \%\right)$, stem number $\left(C V-R^{2}=0.70\right.$, CV-rRMSE $=22.90 \%)$ and DBH $\left(\mathrm{CV}-R^{2}=0.65, \mathrm{CV}-r \mathrm{RMSE}=23.80 \%\right)$; the basal area model had the lowest accuracy $\left(C V-R^{2}=0.63, C V-r\right.$ RMSE $\left.=29.04 \%\right)$. This means that the point cloud, full-waveform and hyperspectral metrics had desirable synergetic effects in the prediction of forest structural parameters.
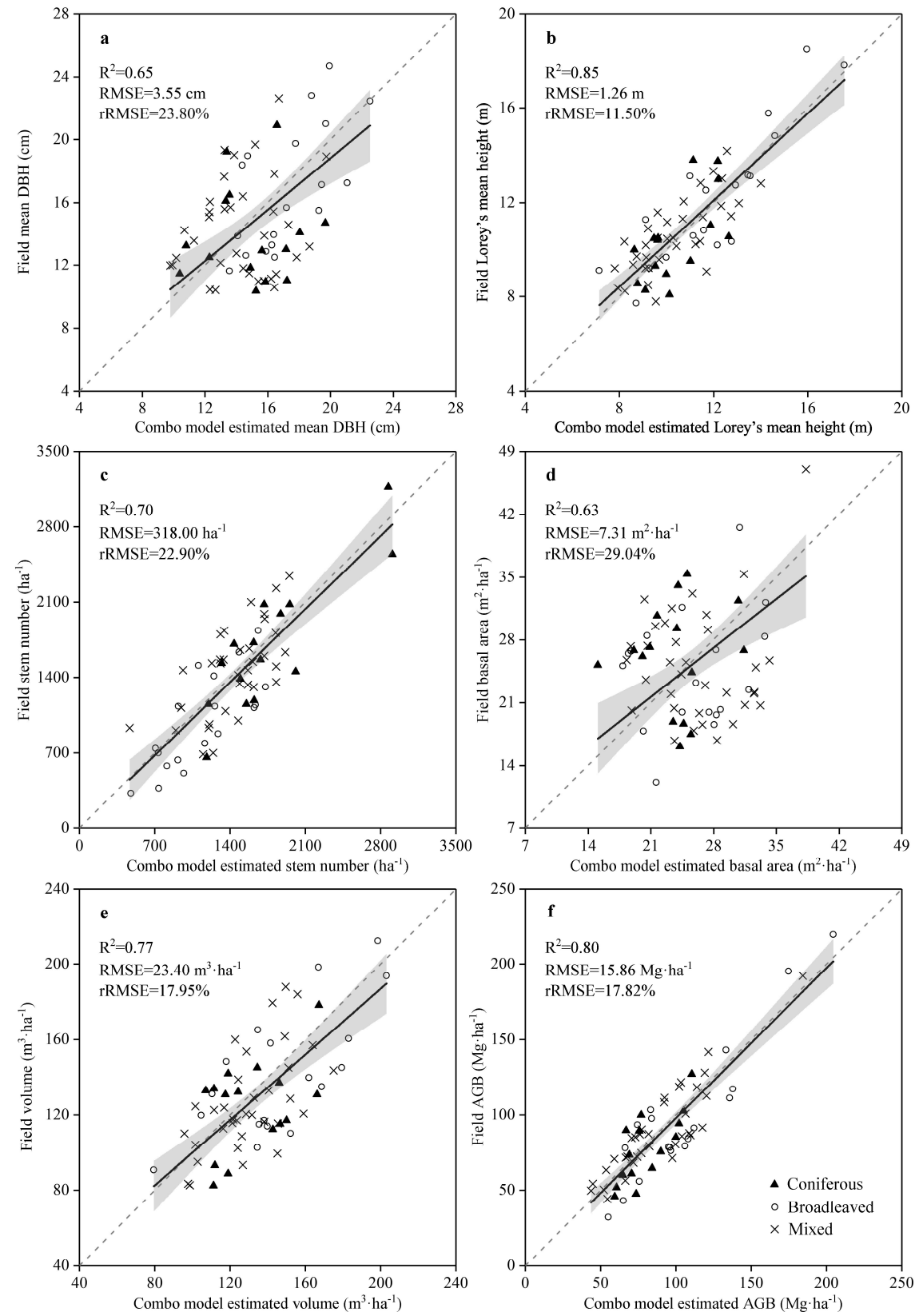

Figure 7. Scatterplots of forest structural parameters between the field surveyed and combo model predicted in cross validation, i.e., forest structural parameters: (a) $\mathrm{DBH}$; (b) $\mathrm{H}_{\mathrm{L}}$; (c) $\mathrm{N}$; (d) G; (e) V; and (f) AGB. 
Table 8. The results of cross validation for the forest structural parameters predictive combo models.

\begin{tabular}{|c|c|c|c|c|c|}
\hline \multirow{2}{*}{ Parameters } & \multirow{2}{*}{$C V-R^{2}$} & \multirow{2}{*}{ CV-rRMSE (\%) } & \multicolumn{3}{|c|}{ Differences in Cross-Validation } \\
\hline & & & ${ }^{\text {a }}$ Mean & Std. dev. & Range \\
\hline $\mathrm{DBH}$ & 0.65 & 23.80 & $0.33 N S$ & 3.56 & $-6.08-6.22$ \\
\hline $\mathrm{H}_{\mathrm{L}}$ & 0.85 & 11.50 & $-0.18 N S$ & 1.26 & $-2.66-2.63$ \\
\hline $\mathrm{N}$ & 0.70 & 22.90 & 44.87 NS & 317.19 & $-504.61-554.17$ \\
\hline G & 0.63 & 29.04 & $0.37 N S$ & 7.36 & $-12.21-12.48$ \\
\hline V & 0.77 & 17.95 & $4.68 N S$ & 23.10 & $-38.39-45.96$ \\
\hline AGB & 0.80 & 17.82 & $2.05 \mathrm{NS}$ & 15.85 & $-22.92-26.91$ \\
\hline
\end{tabular}

Note: See Table 1 for code of forest structural parameters. CV- $R^{2}: R^{2}$ of the result of cross-validation; CV-rRMSE: relative RMSE of the result of cross-validation; ${ }^{a}$ Level of significance: $N S$ represents the mean of differences is not significant $(p>0.05)$.

Figure 8 shows the residuals of six forest structural parameters predicted by models fitted using point cloud metrics, full-waveform LiDAR metrics, and combined full-waveform LiDAR and hyperspectral metrics. It shows that the combo models, which fitted using full-waveform LiDAR and hyperspectral metrics have the smallest variation, followed by the models fitted using full-waveform LiDAR metrics, while the models fitted using point cloud metrics have the largest variation.
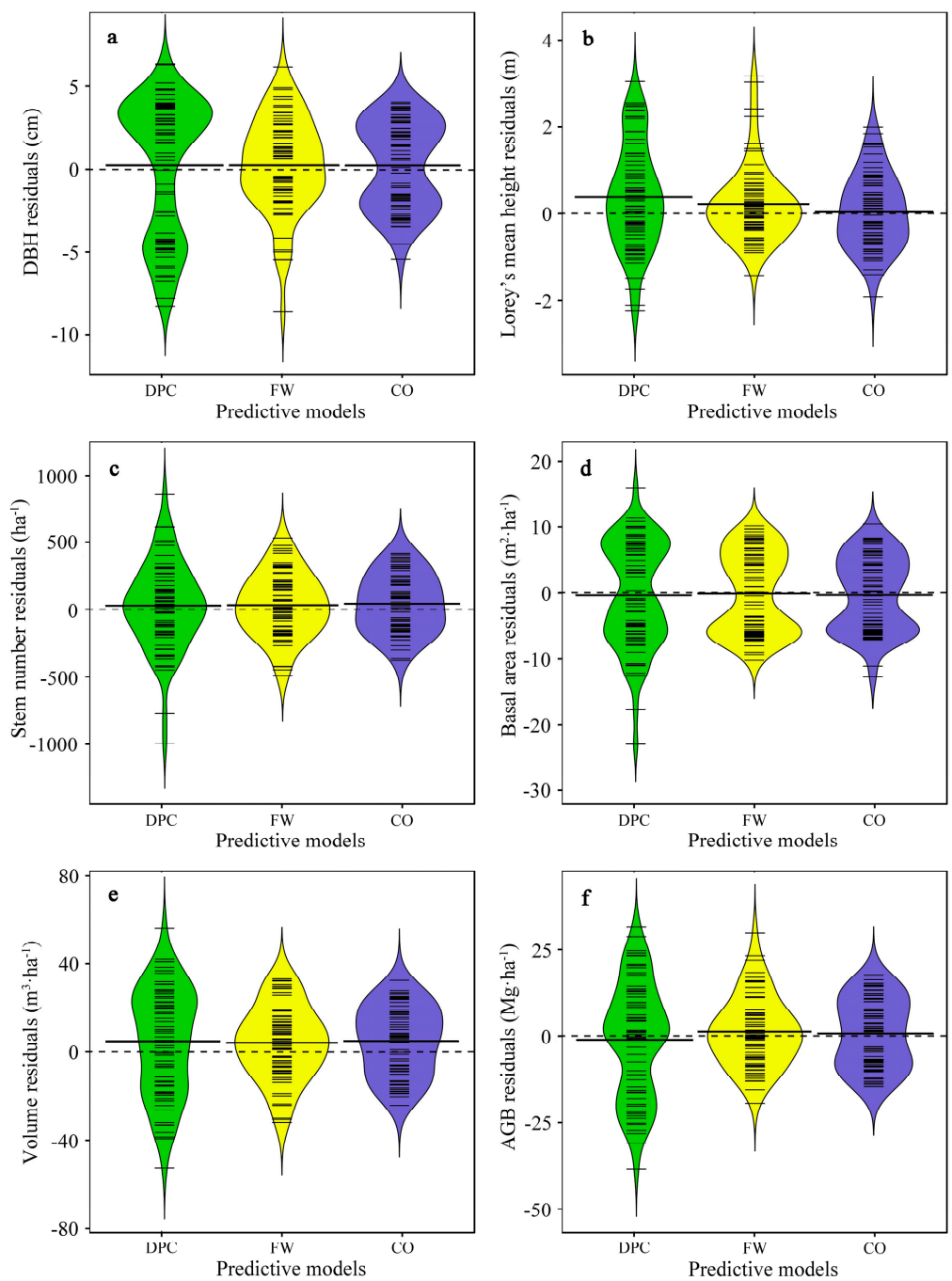

Figure 8. The residuals of six forest structural parameters predicted by DPC based models (DPC), DPC and FW based models (FW), and combo models (CO) which including both LiDAR and hyperspectral metrics, i.e., forest structural parameters: (a) $\mathrm{DBH}_{\text {; }}$ (b) $\mathrm{H}_{\mathrm{L}}$; (c) $\mathrm{N}$; (d) $\mathrm{G}$; (e) V; and (f) AGB. 


\section{Discussion}

\subsection{Synergetic Effects of the Full-Waveform LiDAR and Hyperspectral Data}

In this study, the forest structural parameters in subtropical forests were predicted using simultaneously acquired airborne FWF LiDAR and hyperspectral data. The airborne LiDAR data turned out to be the most applicable remote sensing data in forest structural parameters prediction due to its ability to measure the three dimensional structures of forest canopy $[16,88]$. The hyperspectral data recorded large amounts of continuous narrow bands from VIS to NIR which can provide continuous and detailed spectral signatures of forest biophysical attributes $[89,90]$. Previous studies have demonstrated that the integration of these two complementary datasets can improve the prediction of forest structural parameters [52,57]. It was also proved in this study, although the FWF LiDAR metrics (only DPC or the integration of DPC and FW) can predict forest structural parameters with relatively high accuracy (Adj- $R^{2}=0.52-0.81, r$ RMSE $=15.70-40.87 \%$; Adj- $R^{2}=0.62-0.87, r$ RMSE $=11.01-31.30 \%$ ), the integration of FWF LiDAR metrics and hyperspectral metrics performs better $\left(\right.$ Adj- $R^{2}=0.68-0.88, r$ RMSE $\left.=10.68-28.67 \%\right)$. Zhang et al. [91] predicted six forest structural parameters using only small footprint point cloud LiDAR data in 51 square plots $\left(30 \times 30 \mathrm{~m}^{2}\right)$ in the same study site of subtropical forest. Compared with the results in this study, less variabilities in forest structural parameters were explained (45-77\%). Dalponte et al. [42] predicted stem diameter and volume using integrated small footprint point cloud LiDAR and hyperspectral data in 52 plots in a temperate forest. The results indicated that the improvements in the prediction of stem diameter and volume using integrated LiDAR and hyperspectral data were $0.4 \%$ and $0.5 \%$ ( $r$ RMSE), respectively. Luo et al. [57] predicted AGB using integrated airborne small footprint point cloud LiDAR and hyperspectral data in 33 plots in a northern temperate deciduous forest. It reported that $2.2 \%$ more of the variability in AGB was explained, and $7.9 \%$ less predicted error occurred by using integrated point cloud LiDAR and hyperspectral data. The improvement from using integrated point cloud LiDAR and hyperspectral data was slightly higher than this study. This may be caused by the complex structure of subtropical forest, which is multilayered and has greater variability in DBH and tree height, which reduce the ability of the hyperspectral data to predict forest structural parameters.

In the combo models, the five metrics selected from point cloud, full-waveform and hyperspectral metrics had improved synergetic effects for forest structural parameters prediction. Compared with the DPC based models and FWF LiDAR metrics models, the combo models of six forest structural parameters all performed better, explaining large amounts of variability in forest structural parameters (Table 7). Moreover, in Figure 8 the residuals of the combo models were smaller than FWF LiDAR metrics models, and the residuals of DPC-based models were maximal. The distribution of residuals in the combo models were more convergent and the mean of residuals were closer to zero. Consequently, the combo models were more accurate and robust, which indicated that the integration of FWF LiDAR and hyperspectral data has great potential in the prediction of forest structural parameters in subtropical forest.

\subsection{Implications of Predictive Models}

The parametric regression modeling approach (i.e., backward stepwise regression), which is easy to transplant and can help to understand the relationships between metrics and forest structural parameters, was used to fit predictive models in this study. In Tables 5-7, the final models fitted by backward stepwise regression approach are shown. In these tables, the forest structural parameter of $\mathrm{H}_{\mathrm{L}}$ had the highest accuracy, and this indicated that full-waveform LiDAR data has unique advantages in the prediction of tree height. Previous studies have demonstrated that the tree height predicted by LiDAR data was similar to field-based measurements [92], and the forest structural parameters related to vegetation height were predicted accurately $[93,94]$. In this study, it was also confirmed that the outcomes for volume and AGB had a relatively high accuracy. 
The full-waveform LiDAR data can provide more information compared with point cloud LiDAR data. The full-waveform metrics, such as HOME and WD, were found to be sensitive to the vertical arrangement of canopy elements and canopy height [95,96]. With the addition of full-waveform metrics, the improvement in the accuracy of predictive models was significant (Tables 5 and 6). In particular, for G, V and AGB, the improvement of rRMSE is over $10 \%$. Although the hyperspectral data has limitations in quantifying the vertical structure of forest, the hyperspectral metrics (e.g., NDVI, CRI1 and RVSI, etc.) still have the capability to improve the accuracy of forest structural parameters prediction $(\triangle r$ RMSE $=0.27-2.63 \%)$. This indicates that hyperspectral metrics have great potential in the prediction of forest structural parameters.

\subsection{Availability of Full-Waveform LiDAR and Hyperspectral Metrics}

Point cloud metrics are significantly related to the three-dimensional structural properties of forest canopy, which allow the prediction of the forest structural parameters. Five point cloud metrics, i.e., the 50th percentile height $\left(h_{50}\right)$, 75th percentile height $\left(h_{75}\right)$, 10th canopy return density $\left(d_{1}\right)$, euphotic zones of CVM (E), and the oligophotic zones of CVM $(\mathrm{O})$ were selected to fit the combo models (Table 7). $h_{50}$ and $h_{75}$ were respectively defined as the heights above ground that are $50 \%$ and $75 \%$ of the LiDAR returns below the height. $h_{50}$ likely provides the height of the over-story and $h_{75}$ presents the spatial variability of the canopy height [25]. Thomas et al. [97] reported that the point cloud metrics of $h_{50}$ and $h_{75}$ were strongly related to mean dominated height, basal area, crown closure and AGB. Tsui et al. [25] found that $\mathrm{h}_{50}$ and $\mathrm{h}_{75}$ were the main metrics to explain the majority of the variation in AGB. In the combo models, the $h_{50}$ and $h_{75}$ were selected in the predictive models of AGB and $\mathrm{H}_{\mathrm{L}}$, respectively, and the $r$ RMSE of $\mathrm{AGB}$ and $\mathrm{H}_{\mathrm{L}}$ were $15.14 \%$ and $10.68 \%$, respectively. The $\mathrm{d}_{1}$ was the percentage of points above the 10th quantile to total quantity of points in the plot. This can be used to represent the structure of tree canopy. Previous studies have shown that the $d_{1}$ performed well in the prediction of mean dominated tree height and volume $[18,53]$. In this study, $\mathrm{d}_{1}$ was selected in the prediction of volume and the $r$ RMSE was $16.37 \%$. E and $\mathrm{O}$ were the metrics related to the light extinction in the tree canopy, and are thought to be a three-dimensional analog of cover [69]. They perform well in the prediction of forest structural parameters (e.g., DBH, height, basal area and biomass etc.) [98]. Here, the point cloud metrics of $\mathrm{E}$ and $\mathrm{O}$ were selected in the prediction of stem number and the predictive model of stem number performed well $(r$ RMSE $=20.16 \%)$.

The returned waveforms of the laser system record the specific reflections within the footprint, and are influenced by the materials and vertical structures of canopy. The shape of the returned waveforms can be used to predict forest structural parameters appropriately [7,33]. Sumnall et al. [34] extracted full-waveform metrics (amplitude and echo width variables) from full-waveform data and reported that the full-waveform metrics performed well in the prediction of forest structural parameters (the NRMSE values for the best fit models were in the range of $16-48 \%$ ). In this study, five waveform metrics, i.e., mean of height of median energy $\left(\mathrm{HOME}_{\mu}\right)$, mean of vertical distribution ratio $\left(\mathrm{VDR}_{\mu}\right)$, mean of number of peaks $\left(\mathrm{NP}_{\mu}\right)$, mean of returned waveform energy $\left(\mathrm{RWE}_{\mu}\right)$, and the standard deviation of waveform distance $\left(\mathrm{WD}_{\sigma}\right)$, were selected to fit the combo models (Table 7). $\mathrm{HOME}_{\mu}$ describes the arrangement of canopy materials in the vertical direction and $\mathrm{VDR}_{\mu}$ depicts the change of $\mathrm{HOME}_{\mu}$ relative to the height of canopy. These two metrics help to enhance the interpretation of intermediate tree canopies in the mid-story and suppress the trees in the understory. Therefore, the two full-waveform metrics potentially improved the prediction of forest structural parameters. In the combo models, $\mathrm{HOME}_{\mu}$ and $\mathrm{VDR}_{\mu}$ were selected to predict $\mathrm{V}, \mathrm{DBH}$ and $\mathrm{AGB}$, and the $r \mathrm{RMSE}$ were $16.37 \%, 23.11 \%$ and $15.14 \%$, respectively. $\mathrm{NP}_{\mu}$ and $\mathrm{RWE}_{\mu}$ were the full-waveform metrics used to describe the number of peak and energy of composited waveform, respectively. $\mathrm{NP}_{\mu}$ and $\mathrm{RWE}_{\mu}$ were likely related to the arrangement and density of forest materials, which can be used to represent the forest structure. Thus, $\mathrm{NP}_{\mu}$ and $\mathrm{RWE}_{\mu}$ were selected in the combo predictive models of DBH and $G$, and the $r$ RMSE were $23.11 \%$ and $28.67 \%$, respectively. $W_{\sigma}$ was the full-waveform metric defined as the standard deviation of distances of waveform, which is related to the variation of crown 
height to some extent. It potentially helped in the prediction of forest structure variables related to tree height. In this study, $\mathrm{WD}_{\sigma}$ was selected in the combo prediction of $\mathrm{H}_{\mathrm{L}}$ and it performed well $(r$ RMSE $=10.68 \%)$.

Previous studies have demonstrated that hyperspectral metrics have unique effects in the prediction of forest structural parameters. In this study, the integrated usage of FWF LiDAR and hyperspectral metrics improved the accuracies of forest structural parameters. Compared with the prediction using point cloud metrics only, the improvements in prediction were significant $\left(\triangle \mathrm{Adj}-R^{2}=0.07-0.16, \Delta r \mathrm{RMSE}=5.02-13.91 \%\right)$. Compared with the prediction using point cloud and full-waveform metrics, the improvements in prediction were distinct $\left(\Delta \mathrm{Adj}-R^{2}=0.01-0.07\right.$, $\Delta r \mathrm{RMSE}=0.27-2.63 \%$ ). In this study, five hyperspectral metrics, i.e., normalized difference vegetation index (NDVI), red-edge vegetation stress index (RVSI), atmospherically resistant vegetation index (ARVI), carotenoid reflectance index 1 (CRI1) and the second component of PCA transformation (PCA2), were selected to fit the combo models (Table 7). Many studies have indicated that the NDVI and ARVI are correlated with forest structures such as the leaf area index (LAI) and forest AGB [58,99,100]. Latifi et al. [23] reported that the ARVI was also correlated with mean height. Wang et al. [101] extracted NDVI and ARVI from hyperspectral data and reported that the biomass predictive models performed well using the two metrics ( $r$ RMSE $=13.9 \%$ and $15.8 \%$ ). In the combo models, NDVI and ARVI were selected to predict $\mathrm{H}_{\mathrm{L}}, \mathrm{AGB}$ and $\mathrm{G}$, and the $r$ RMSE was $10.68 \%, 15.14 \%$ and $28.67 \%$, respectively. RVSI was the hyperspectral metric used to identify vegetation stress trends based on the spectral shifting of red-edge. CRI1 is a metric representing reflectance of carotenoid, which was directly correlated with the content of carotenoid. The RVSI and CRI1 potentially improved the prediction of forest structural parameters due to the profound influences of stress and photosynthetic pigments in the forest structure formation. The RVSI and CRI1 were selected in the combo models of N and DBH, and the $r$ RMSE were $20.16 \%$ and $23.11 \%$, respectively. PCA analysis was widely used to reduce the dimensions of the dataset. In general, the first several components contain the most of variance in the dataset. In this study, PCA2 contained much more variances of hyperspectral reflectance channels and might d perform well in the prediction of forest structural parameters. In the combo models, PCA2 was selected to predict $\mathrm{V}$ and the $r$ RMSE of prediction was $16.37 \%$.

The full-waveform LiDAR metrics (including point cloud and full-waveform metrics) have the ability to record the forest structure in detail. In Figure 4, the vertical distribution of point cloud and pulse energy indicate the distribution of forest materials and the transmission of energy in the canopy. The hyperspectral metrics are associated with the biophysical and biochemical attributes of forest, which can be used to reflect the health conditions and growth stage of forest vegetation (e.g., Figure 4 (III)). Therefore, the full-waveform LiDAR metrics, hyperspectral metrics and the forest structural parameters predicted in this study can be used to assess the structural, compositional and functional properties of forest ecosystems. Moreover, the forest nutritional status, wildlife habitat, and ecosystem service value can also be evaluated using the full-waveform LiDAR and hyperspectral data.

\subsection{Potential Improvements and Indications for Future Research}

This study combined full-waveform LiDAR and hyperspectral data in the feature level, and the addition of hyperspectral metrics in full-waveform LiDAR metrics improved the accuracy of forest structural parameters. In the future, more advanced approaches associated with physical theory or the mechanisms of sensors will be used to explore the better integration of full-waveform LiDAR and hyperspectral data. Moreover, the non-parametric modeling approach can be used to enhance the capability of prediction of forest structural parameters in subtropical forests.

\section{Conclusions}

Simultaneously acquired airborne full-waveform (FWF) LiDAR and hyperspectral data were used to predict forest structural parameters in subtropical forests of southeast China. The pulse amplitude and waveform shape of airborne full-waveform LiDAR data (FWF) were calibrated using a physical 
process-driven and a voxel-based approach, respectively. Different suites of LiDAR and hyperspectral metrics were calculated and selected using correlation analysis and principal component analysis (PCA). The selected point cloud, full-waveform and hyperspectral metrics were used to fit regression models individually and in integration to predict six forest structural parameters, and the capability of predictive models and synergetic effects of metrics were assessed using leave-one-out cross validation. The results showed that: most of the metrics selected from three groups divided by the PCA analysis, which were highly correlated with the first and second principal component, had a weak relationship with each other $(r<0.7)$; the prediction of $\mathrm{H}_{\mathrm{L}}$ using the metrics of $\mathrm{h}_{75}, \mathrm{WD}_{\sigma}$ and NDVI had a relatively higher accuracy (Adjusted- $R^{2}=0.88$, relative RMSE $=10.68 \%$ ) than the other forest structural parameters; and the usage of DPC and FW resulted in higher accuracies (Adjusted- $R^{2}=0.62-0.87$, relative RMSE $=11.01-31.30 \%$ ) than the models only including DPC (Adjusted- $R^{2}=0.52-0.81$, relative RMSE $=15.70-40.87 \%)$. Moreover, the integration of DPC, FW and HS had a positive synergetic effect for forest structural parameters prediction (Adjusted- $R^{2}=0.68-0.88$, relative RMSE $=10.68-28.67 \%$ ).

Author Contributions: X.S. analyzed the data and wrote the paper. L.C. helped in project and study design, paper writing, and analysis. D.C., Y.S., G.W. and H.R. helped in field work and data analysis.

Funding: This research was funded by the National Natural Science Foundation of China (grant number 31770590). It was also funded by the Doctorate Fellowship Foundation of Nanjing Forestry University and the Priority Academic Program Development of Jiangsu Higher Education Institutions (PAPD).

Acknowledgments: The authors gratefully acknowledge the foresters in Yushan forest for their assistance with data collection and sharing their rich knowledge and working experience of the local forest ecosystems.

Conflicts of Interest: The authors declare no conflict of interest.

\section{Appendix A}

Table A1. Allometric equations used in this study for aboveground biomass calculation.

\begin{tabular}{llllll}
\hline Tree Species & Component & $\mathbf{a}$ & $\mathbf{b}$ & $\boldsymbol{R}^{\mathbf{2}}$ & References \\
\hline \multirow{3}{*}{ Masson pine } & Stem wood $\left(W_{\mathrm{s}}\right)$ & 0.141 & 1.092 & 0.9970 & \\
& Live branches $\left(W_{\mathrm{b}}\right)$ & 0.065 & 0.991 & 0.9871 & [102] \\
& Foliage $\left(W_{\mathrm{f}}\right)$ & 0.132 & 0.745 & 0.9827 & \\
\hline \multirow{3}{*}{ Chinese fir } & Stem wood $\left(W_{\mathrm{s}}\right)$ & 0.124 & 0.680 & 0.9704 & \\
& Live branches $\left(W_{\mathrm{b}}\right)$ & 0.203 & 0.385 & 0.7223 & [103] \\
& Foliage $\left(W_{\mathrm{f}}\right)$ & 0.850 & 0.189 & 0.6567 & \\
\hline \multirow{3}{*}{ Slash pine } & Stem wood $\left(W_{\mathrm{s}}\right)$ & 0.235 & 0.900 & 0.9523 & \\
& Live branches $\left(W_{\mathrm{b}}\right)$ & 0.080 & 1.064 & 0.8520 & [104] \\
& Foliage $\left(W_{\mathrm{f}}\right)$ & 0.456 & 0.610 & 0.8802 & \\
\hline \multirow{3}{*}{ Sawtooth oak } & Stem wood $\left(W_{\mathrm{s}}\right)$ & 0.018 & 1.034 & 0.9864 & \\
& Live branches $\left(W_{\mathrm{b}}\right)$ & 0.00008 & 1.468 & 0.9745 & [105] \\
& Foliage $\left(W_{\mathrm{f}}\right)$ & 0.004 & 0.769 & 0.8662 & \\
\hline \multirow{3}{*}{ Sweet gum } & Stem wood $\left(W_{\mathrm{s}}\right)$ & 0.093 & 0.801 & 0.9310 & \\
& Live branches $\left(W_{\mathrm{b}}\right)$ & 0.083 & 0.649 & 0.9890 & [106] \\
& Foliage $\left(W_{\mathrm{f}}\right)$ & 1.084 & 0.217 & 0.6940 & \\
\hline \multirow{2}{*}{ Other broadleaves } & Stem wood $\left(W_{\mathrm{s}}\right)$ & 0.023 & 0.985 & 0.9903 & \\
& Live branches $\left(W_{\mathrm{b}}\right)$ & 0.00004 & 3.785 & 0.9623 & [107] \\
\hline
\end{tabular}

Note: Each biomass component was calculated using the equation of $W=\mathrm{a}\left(D^{2} H\right)^{\mathrm{b}}$, where $H$ is the tree height $(\mathrm{m})$, $D$ is the $\mathrm{DBH}(\mathrm{cm})$ and $\mathrm{a}, \mathrm{b}$ are the parameters. 
Table A2. Equations used in this study for volume calculation.

\begin{tabular}{lllllc}
\hline Tree Species & $\mathbf{a}$ & $\mathbf{b}$ & $\mathbf{c}$ & $\boldsymbol{R}^{\mathbf{2}}$ & References \\
\hline Masson pine & 0.000056 & 1.9980 & 0.8470 & 0.9649 & {$[108]$} \\
Chinese fir & 0.000062 & 1.8520 & 1.0080 & 0.9956 & {$[109]$} \\
Slash pine & 0.000067 & 1.9952 & 0.7908 & 0.9523 & {$[110]$} \\
Sawtooth oak & 0.000033 & 2.0000 & 1.0000 & 0.9930 & {$[111]$} \\
Sweet gum & 0.000053 & 1.8822 & 1.0093 & 0.9810 & {$[112]$} \\
Other broadleaves & 0.000067 & 1.9600 & 0.8144 & 0.9900 & {$[111]$} \\
\hline
\end{tabular}

Note: Tree volume was calculated using the equation of $V=\mathrm{a} D^{\mathrm{b}} H^{\mathrm{c}}$, where $H$ is the tree height $(\mathrm{m}), D$ is the DBH $(\mathrm{cm})$ and $\mathrm{a}, \mathrm{b}, \mathrm{c}$ are the parameters.

\section{References}

1. FAO. Global Forest Resources Assessment; Food and Agriculture Organization: Rome, Italy, 2010; Volume 163.

2. Pan, Y.; Birdsey, R.A.; Phillips, O.L.; Jackson, R.B. The Structure, Distribution, and Biomass of the World's Forests. Annu. Rev. Ecol. Evol. Syst. 2013, 44, 593-622. [CrossRef]

3. Wang, X.-H.; Kent, M.; Fang, X.-F. Evergreen broad-leaved forest in Eastern China: Its ecology and conservation and the importance of resprouting in forest restoration. For. Ecol. Manag. 2007, 245, 76-87. [CrossRef]

4. Pan, Y.; Birdsey, R.A.; Fang, J.; Houghton, R.; Kauppi, P.E.; Kurz, W.A.; Phillips, O.L.; Shvidenko, A.; Lewis, S.L.; Canadell, J.G.; et al. A large and persistent carbon sink in the world's forests. Science 2011, 333, 988-993. [CrossRef] [PubMed]

5. Spies, T.A. Forest Structure: A Key to the Ecosystem. Northwest Sci. 1998, 72, 34-39.

6. Lovell, J.L.; Jupp, D.L.B.; Culvenor, D.S.; Coops, N.C. Using airborne and ground-based ranging lidar to measure canopy structure in Australian forests. Can. J. Remote Sens. 2003, 29, 607-622. [CrossRef]

7. Jung, J.; Crawford, M.M. Extraction of features from LIDAR waveform data for characterizing forest structure. IEEE Geosci. Remote Sens. Lett. 2012, 9, 492-496. [CrossRef]

8. Mohammadi, J.; Shataee, S.; Namiranian, M.; Næsset, E. Modeling biophysical properties of broad-leaved stands in the hyrcanian forests of Iran using fused airborne laser scanner data and ultraCam-D images. Int. J. Appl. Earth Obs. Geoinf. 2017, 61, 32-45. [CrossRef]

9. Meng, Q.; Cieszewski, C.; Madden, M. Large area forest inventory using Landsat ETM+: A geostatistical approach. ISPRS J. Photogramm. Remote Sens. 2009, 64, 27-36. [CrossRef]

10. Shataee, S.; Kalbi, S.; Fallah, A.; Pelz, D. Forest attribute imputation using machine-learning methods and ASTER data: Comparison of k-NN, SVR and random forest regression algorithms. Int. J. Remote Sens. 2012, 33, 6254-6280. [CrossRef]

11. Foody, G.M. Remote sensing of tropical forest environments: Towards the monitoring of environmental resources for sustainable development. Int. J. Remote Sens. 2003, 24, 4035-4046. [CrossRef]

12. Wulder, M.A.; White, J.C.; Nelson, R.F.; Næsset, E.; Ole, H.; Coops, N.C.; Hilker, T.; Bater, C.W.; Gobakken, T. Remote Sensing of Environment Lidar sampling for large-area forest characterization: A review. Remote Sens. Environ. 2012, 121, 196-209. [CrossRef]

13. Buddenbaum, H.; Seeling, S.; Hill, J. Fusion of full-waveform lidar and imaging spectroscopy remote sensing data for the characterization of forest stands. Int. J. Remote Sens. 2013, 34, 4511-4524. [CrossRef]

14. Gibbs, H.K.; Brown, S.; Niles, J.O.; Foley, J.A. Monitoring and estimating tropical forest carbon stocks: Making REDD a reality. Environ. Res. Lett. 2007, 2. [CrossRef]

15. Toth, C.; Jóźków, G. Remote sensing platforms and sensors: A survey. ISPRS J. Photogramm. Remote Sens. 2016, 115, 22-36. [CrossRef]

16. Koch, B. Status and future of laser scanning, synthetic aperture radar and hyperspectral remote sensing data for forest biomass assessment. ISPRS J. Photogramm. Remote Sens. 2010, 65, 581-590. [CrossRef]

17. Swatantran, A.; Dubayah, R.; Roberts, D.; Hofton, M.; Blair, J.B. Mapping biomass and stress in the Sierra Nevada using lidar and hyperspectral data fusion. Remote Sens. Environ. 2011, 115, 2917-2930. [CrossRef]

18. Ozdemir, I.; Karnieli, A. Predicting forest structural parameters using the image texture derived from worldview-2 multispectral imagery in a dryland forest, Israel. Int. J. Appl. Earth Obs. Geoinf. 2011, 13, 701-710. [CrossRef] 
19. Drake, J.B.; Dubayah, R.O.; Knox, R.G.; Clark, D.B.; Blair, J.B. Sensitivity of large-footprint lidar to canopy structure and biomass in a neotropical rainforest. Remote Sens. Environ. 2002, 81, 378-392. [CrossRef]

20. Koetz, B.; Morsdorf, F.; Sun, G.; Ranson, K.J.; Itten, K.; Allgöwer, B. Inversion of a lidar waveform model for forest biophysical parameter estimation. IEEE Geosci. Remote Sens. Lett. 2006, 3, 49-53. [CrossRef]

21. Popescu, S.C. Estimating biomass of individual pine trees using airborne lidar. Biomass Bioenergy 2007, 31, 646-655. [CrossRef]

22. Coops, N.C.; Hilker, T.; Wulder, M.A.; St-Onge, B.; Newnham, G.; Siggins, A.; Trofymow, J.A. Estimating canopy structure of Douglas-fir forest stands from discrete-return LiDAR. Trees Struct. Funct. 2007, 21, 295-310. [CrossRef]

23. Latifi, H.; Fassnacht, F.; Koch, B. Forest structure modeling with combined airborne hyperspectral and LiDAR data. Remote Sens. Environ. 2012, 121, 10-25. [CrossRef]

24. Næsset, E.; Økland, T. Estimating tree height and tree crown properties using airborne scanning laser in a boreal nature reserve. Remote Sens. Environ. 2002, 79, 105-115. [CrossRef]

25. Tsui, O.W.; Coops, N.C.; Wulder, M.A.; Marshall, P.L.; McCardle, A. Using multi-frequency radar and discrete-return LiDAR measurements to estimate above-ground biomass and biomass components in a coastal temperate forest. ISPRS J. Photogramm. Remote Sens. 2012, 69, 121-133. [CrossRef]

26. Cao, L.; Gao, S.; Li, P.; Yun, T.; Shen, X.; Ruan, H. Aboveground biomass estimation of individual trees in a coastal planted forest using full-waveform airborne laser scanning data. Remote Sens. 2016, 8, 729. [CrossRef]

27. Wagner, W. Radiometric calibration of small-footprint full-waveform airborne laser scanner measurements: Basic physical concepts. ISPRS J. Photogramm. Remote Sens. 2010, 65, 505-513. [CrossRef]

28. Reitberger, J.; Krzystek, P.; Stilla, U. Benefit of Airborne Full Waveform LIDAR for 3D segmentation and classification of single trees. In Proceedings of the ASPRS 2009 Annual Conference, Baltimore, MD, USA, 9-13 March 2009; pp. 17-19.

29. Mallet, C.; Bretar, F. Full-waveform topographic lidar: State-of-the-art. ISPRS J. Photogramm. Remote Sens. 2009, 64, 1-16. [CrossRef]

30. Reitberger, J.; Schnörr, C.; Krzystek, P.; Stilla, U. 3D segmentation of single trees exploiting full waveform LIDAR data. ISPRS J. Photogramm. Remote Sens. 2009, 64, 561-574. [CrossRef]

31. Wagner, W.; Ullrich, A.; Ducic, V.; Melzer, T.; Studnicka, N. Gaussian decomposition and calibration of a novel small-footprint full-waveform digitising airborne laser scanner. ISPRS J. Photogramm. Remote Sens. 2006, 60, 100-112. [CrossRef]

32. Pirotti, F.; Laurin, G.V.; Vettore, A.; Masiero, A.; Valentini, R. Small footprint full-waveform metrics contribution to the prediction of biomass in tropical forests. Remote Sens. 2014, 6, 9576-9599. [CrossRef]

33. Lindberg, E.; Olofsson, K.; Holmgren, J.; Olsson, H. Estimation of 3D vegetation structure from waveform and discrete return airborne laser scanning data. Remote Sens. Environ. 2012, 118, 151-161. [CrossRef]

34. Sumnall, M.J.; Hill, R.A.; Hinsley, S.A. Comparison of small-footprint discrete return and full waveform airborne lidar data for estimating multiple forest variables. Remote Sens. Environ. 2016, 173, $214-223$. [CrossRef]

35. Yao, W.; Krzystek, P.; Heurich, M. Tree species classification and estimation of stem volume and DBH based on single tree extraction by exploiting airborne full-waveform LiDAR data. Remote Sens. Environ. 2012, 123, 368-380. [CrossRef]

36. Shaw, G.; Manolakis, D. Signal processing for hyperspectral image exploitation. IEEE Signal Process. Mag. 2002, 19, 12-16. [CrossRef]

37. Brovkina, O.; Novotny, J.; Cienciala, E.; Zemek, F.; Russ, R. Mapping forest aboveground biomass using airborne hyperspectral and LiDAR data in the mountainous conditions of Central Europe. Ecol. Eng. 2017, 100, 219-230. [CrossRef]

38. Odagawa, S.; Okada, K. Tree species discrimination using continuum removed airborne hyperspectral data. In Proceedings of the 2009 First Workshop on Hyperspectral Image and Signal Processing: Evolution in Remote Sensing, Grenoble, France, 26-28 August 2009; pp. 1-4. [CrossRef]

39. Kalacska, M.; Sanchez-Azofeifa, G.A.; Rivard, B.; Caelli, T.; White, H.P.; Calvo-Alvarado, J.C. Ecological fingerprinting of ecosystem succession: Estimating secondary tropical dry forest structure and diversity using imaging spectroscopy. Remote Sens. Environ. 2007, 108, 82-96. [CrossRef]

40. Clark, M.L.; Roberts, D.A.; Clark, D.B. Hyperspectral discrimination of tropical rain forest tree species at leaf to crown scales. Remote Sens. Environ. 2005, 96, 375-398. [CrossRef] 
41. Shen, X.; Cao, L. Tree-species classification in subtropical forests using airborne hyperspectral and LiDAR data. Remote Sens. 2017, 9, 1180. [CrossRef]

42. Dalponte, M.; Frizzera, L.; Gianelle, D. Fusion of Hyperspectral and LiDAR Data for Forest Attributes Estimation. In Proceedings of the 2014 IEEE Geoscience and Remote Sensing Symposium (IGARSS), Quebec, QC, Canada, 13-18 July 2014; pp. 788-791.

43. Mitchell, J.J.; Shrestha, R.; Spaete, L.P.; Glenn, N.F. Combining airborne hyperspectral and LiDAR data across local sites for upscaling shrubland structural information: Lessons for HyspIRI. Remote Sens. Environ. 2015, 167, 98-110. [CrossRef]

44. Anderson, J.E.; Plourde, L.C.; Martin, M.E.; Braswell, B.H.; Smith, M.L.; Dubayah, R.O.; Hofton, M.A.; Blair, J.B. Integrating waveform lidar with hyperspectral imagery for inventory of a northern temperate forest. Remote Sens. Environ. 2008, 112, 1856-1870. [CrossRef]

45. Wani, A.A.; Joshi, P.K.; Singh, O. Estimating biomass and carbon mitigation of temperate coniferous forests using spectral modeling and field inventory data. Ecol. Inform. 2015, 25, 63-70. [CrossRef]

46. Shen, X.; Cao, L.; Liu, K.; She, G.; Ruan, H. Aboveground biomass estimation in a subtropical forest using airborne hyperspectral data. In Proceedings of the 2016 4th International Workshop on Earth Observation and Remote Sensing Applications (EORSA), Guangzhou, China, 4-6 July 2016; pp. 1-4. [CrossRef]

47. Schlerf, M.; Atzberger, C.; Hill, J. Remote sensing of forest biophysical variables using HyMap imaging spectrometer data. Remote Sens. Environ. 2005, 95, 177-194. [CrossRef]

48. Singh, A.K.; Kumar, H.V.; Kadambi, G.R.; Kishore, J.K.; Shuttleworth, J.; Manikandan, J. Quality metrics evaluation of hyperspectral images. In International Archives of the Photogrammetry, Remote Sensing and Spatial Information Sciences-ISPRS Archives; ISPRS Technical Commission VIII Symposium: Hyderabad, India, 2014; Volume 40, pp. 1221-1226.

49. Clark, M.L.; Roberts, D.A.; Ewel, J.J.; Clark, D.B. Estimation of tropical rain forest aboveground biomass with small-footprint lidar and hyperspectral sensors. Remote Sens. Environ. 2011, 115, 2931-2942. [CrossRef]

50. Pu, R.; Gong, P.; Biging, G.S.; Larrieu, M.R. Extraction of red edge optical parameters from hyperion data for estimation of forest leaf area index. IEEE Trans. Geosci. Remote Sens. 2003, 41, 916-921.

51. Thenkabail, P.S.; Enclona, E.A.; Ashton, M.S.; Legg, C.; De Dieu, M.J. Hyperion, IKONOS, ALI, and ETM+ sensors in the study of African rainforests. Remote Sens. Environ. 2004, 90, 23-43. [CrossRef]

52. Vaglio Laurin, G.; Chen, Q.; Lindsell, J.A.; Coomes, D.A.; Del Frate, F.; Guerriero, L.; Pirotti, F.; Valentini, R. Above ground biomass estimation in an African tropical forest with lidar and hyperspectral data. ISPRS J. Photogramm. Remote Sens. 2014, 89, 49-58. [CrossRef]

53. Kandare, K.; Dalponte, M.; Ørka, H.O.; Frizzera, L.; Næsset, E. Prediction of species-specific volume using different inventory approaches by fusing airborne laser scanning and hyperspectral data. Remote Sens. 2017, 9, 400. [CrossRef]

54. Zhang, H.; Hu, H.; Yao, X.G.; Zheng, K.F.; Gan, Y. Estimation of above-ground biomass using HJ-1 hyperspectral images in Hangzhou Bay, China. In Proceedings of the 2009 International Conference on Information Engineering and Computer Science (ICIECS 2009), Wuhan, China, 19-20 December 2009.

55. Chen, J.; Gu, S.; Shen, M.; Tang, Y.; Matsushita, B. Estimating aboveground biomass of grassland having a high canopy cover: An exploratory analysis of in situ hyperspectral data. Int. J. Remote Sens. 2009, 30, 6497-6517. [CrossRef]

56. Jones, T.G.; Coops, N.C.; Sharma, T. Assessing the utility of airborne hyperspectral and LiDAR data for species distribution mapping in the coastal Pacific Northwest, Canada. Remote Sens. Environ. 2010, 114, 2841-2852. [CrossRef]

57. Luo, S.; Wang, C.; Xi, X.; Pan, F.; Peng, D.; Zou, J.; Nie, S.; Qin, H. Fusion of airborne LiDAR data and hyperspectral imagery for aboveground and belowground forest biomass estimation. Ecol. Indic. 2017, 73, 378-387. [CrossRef]

58. Wang, H.; Glennie, C. Fusion of waveform LiDAR data and hyperspectral imagery for land cover classification. ISPRS J. Photogramm. Remote Sens. 2015, 108, 1-11. [CrossRef]

59. Cao, L.; Coops, N.C.; Innes, J.L.; Sheppard, S.R.J.; Fu, L.; Ruan, H.; She, G. Estimation of forest biomass dynamics in subtropical forests using multi-temporal airborne LiDAR data. Remote Sens. Environ. 2016, 178, 158-171. [CrossRef]

60. Pang, Y.; Li, Z.; Ju, H.; Lu, H.; Jia, W.; Si, L.; Guo, Y.; Liu, Q.; Li, S.; Liu, L.; et al. LiCHy: The CAF's LiDAR, CCD and hyperspectral integrated airborne observation system. Remote Sens. 2016, 8, 398. [CrossRef] 
61. Duong, H. Processing and Application of ICESat Large Footprint Full Waveform Laser Range Data; TU Delft: Delft, The Netherlands, 2010; ISBN 9789090254784.

62. Vaughn, N.R.; Moskal, L.M.; Turnblom, E.C. Tree species detection accuracies using discrete point lidar and airborne waveform lidar. Remote Sens. 2012, 4, 377-403. [CrossRef]

63. Reitberger, J.; Krzystek, P.; Stilla, U. Analysis of full waveform LIDAR data for the classification of deciduous and coniferous trees. Int. J. Remote Sens. 2008, 29, 1407-1431. [CrossRef]

64. Yang, W.; Ni-Meister, W.; Lee, S. Assessment of the impacts of surface topography, off-nadir pointing and vegetation structure on vegetation lidar waveforms using an extended geometric optical and radiative transfer model. Remote Sens. Environ. 2011, 115, 2810-2822. [CrossRef]

65. Neuenschwander, A.L. Evaluation of waveform deconvolution and decomposition retrieval algorithms for ICESat/GLAS data. Can. J. Remote Sens. 2008, 34, S240-S246. [CrossRef]

66. Cao, L.; Coops, N.C.; Innes, J.L.; Dai, J.; Ruan, H.; She, G. Tree species classification in subtropical forests using small-footprint full-waveform LiDAR data. Int. J. Appl. Earth Obs. Geoinf. 2016, 49, 39-51. [CrossRef]

67. Hermosilla, T.; Coops, N.C.; Ruiz, L.A.; Moskal, L.M. Deriving pseudo-vertical waveforms from small-footprint full-waveform LiDAR data. Remote Sens. Lett. 2014, 5, 332-341. [CrossRef]

68. Andersen, H.E.; McGaughey, R.J.; Reutebuch, S.E. Estimating forest canopy fuel parameters using LIDAR data. Remote Sens. Environ. 2005, 94, 441-449. [CrossRef]

69. Lefsky, M.A.; Cohen, W.B.; Acker, S.A.; Parker, G.G.; Spies, T.A.; Harding, D. Lidar remote sensing of the canopy structure and biophysical properties of Douglas-fir western hemlock forests. Remote Sens. Environ. 1999, 70, 339-361. [CrossRef]

70. Asner, G.P. Biophysical and biochemical sources of variability in canopy reflectance. Remote Sens. Environ. 1998, 64, 234-253. [CrossRef]

71. Jordan, C.F. Derivation of Leaf-Area Index from Quality of Light on the Forest Floor. Ecology 1969, 50, 663-666. [CrossRef]

72. Rouse, J.W.; Haas, R.H.; Schell, J.A.; Deering, D.W. Monitoring Vegetation Systems in the Great Okains with ERTS. In Third Earth Resources Technology Satellite-1 Symposium; NASA: Washington, DC, USA, 1973; Volume 1, pp. 325-333.

73. Huete, A.; Didan, K.; Miura, T.; Rodriguez, E.P.; Gao, X.; Ferreira, L.G. Overview of the radiometric and biophysical performance of the MODIS vegetation indices. Remote Sens. Environ. 2002, 83, 195-213. [CrossRef]

74. Gitelson, A.A.; Merzlyak, M.N. Signature Analysis of Leaf Reflectance Spectra: Algorithm Development for Remote Sensing of Chlorophyll. J. Plant Physiol. 1996, 148, 494-500. [CrossRef]

75. Huete, A.R. A soil-adjusted vegetation index (SAVI). Remote Sens. Environ. 1988, 25, 295-309. [CrossRef]

76. Kaufman, Y.J.; Tanré, D. Strategy for direct and indirect methods for correcting the aerosol effect on remote sensing: From AVHRR to EOS-MODIS. Remote Sens. Environ. 1996, 55, 65-79. [CrossRef]

77. Merton, R.; Huntington, J. Early Simulation Results of the Aries-1 Satellite Sensor for Multi-Temporal Vegetation Research Derived from Aviris. In Proceedings of the Eighth Annual JPL Airborne Earth Science Workshop, Pasadena, CA, USA, 9-11 February 1999; pp. 1-10.

78. Merzlyak, M.N.; Gitelson, A.A.; Chivkunova, O.B.; Rakitin, V.Y. Non-destructive optical detection of pigment changes during leaf senescence and fruit ripening. Physiol. Plant. 1999, 106, 135-141. [CrossRef]

79. Vogelmann, J.E.; Rock, B.N.; Moss, D.M. Red edge spectral measurements from sugar maple leaves. Int. J. Remote Sens. 1993, 14, 1563-1575. [CrossRef]

80. Gamon, J.A.; Surfus, J.S. Assessing leaf pigment content and activity with a reflectometer. New Phytol. 1999, 143, 105-117. [CrossRef]

81. Barton, C.V.M.; North, P.R.J. Remote sensing of canopy light use efficiency using the photochemical reflectance index model and sensitivity analysis. Remote Sens. Environ. 2001, 78, 264-273. [CrossRef]

82. Zheng, T.; Chen, J.M. Photochemical reflectance ratio for tracking light use efficiency for sunlit leaves in two forest types. ISPRS J. Photogramm. Remote Sens. 2017, 123, 47-61. [CrossRef]

83. Penuelas, J.; Pinol, J.; Ogaya, R.; Filella, I. Estimation of plant water concentration by the reflectance Water Index WI (R900/R970). Int. J. Remote Sens. 1997, 18, 2869-2875. [CrossRef]

84. Gitelson, A.A.; Zur, Y.; Chivkunova, O.B.; Merzlyak, M.N. Assessing carotenoid content in plant leaves with reflectance spectroscopy. Photochem. Photobiol. 2002, 75, 272-281. [CrossRef] 
85. Gitelson, A.A.; Merzlyak, M.N.; Chivkunova, O.B. Optical Properties and Nondestructive Estimation of Anthocyanin Content in Plant Leaves. Photochem. Photobiol. 2001, 74, 38-45. [CrossRef]

86. Luo, S.; Wang, C.; Xi, X.; Zeng, H.; Li, D.; Xia, S.; Wang, P. Fusion of airborne discrete-return LiDAR and hyperspectral data for land cover classification. Remote Sens. 2016, 8, 3. [CrossRef]

87. Silva, C.A.; Klauberg, C.; Hudak, A.T.; Vierling, L.A.; Liesenberg, V.; Carvalho, S.P.C.E.; Rodriguez, L.C.E. A principal component approach for predicting the stem volume in Eucalyptus plantations in Brazil using airborne LiDAR data. Forestry 2016, 89, 422-433. [CrossRef]

88. Hyyppä, J.; Hyyppä, H.; Leckie, D.; Gougeon, F.; Yu, X.; Maltamo, M. Review of methods of small-footprint airborne laser scanning for extracting forest inventory data in boreal forests. Int. J. Remote Sens. 2008, 29, 1339-1366. [CrossRef]

89. Treitz, P.M.; Howarth, P.J. Hyperspectral remote sensing for estimating biophysical parameters of forest ecosystems. Prog. Phys. Geogr. 1999, 23, 359-390. [CrossRef]

90. Man, Q.; Dong, P.; Guo, H.; Liu, G.; Shi, R. Light detection and ranging and hyperspectral data for estimation of forest biomass: A review. J. Appl. Remote Sens. 2014, 8, 081598. [CrossRef]

91. Zhang, Z.; Cao, L.; She, G. Estimating forest structural parameters using canopy metrics derived from airborne LiDAR data in subtropical forests. Remote Sens. 2017, 9, 940. [CrossRef]

92. Næsset, E. Predicting forest stand characteristics with airborne scanning laser using a practical two-stage procedure and field data. Remote Sens. Environ. 2002, 80, 88-99. [CrossRef]

93. Babcock, C.; Finley, A.O.; Cook, B.D.; Weiskittel, A.; Woodall, C.W. Modeling forest biomass and growth: Coupling long-term inventory and LiDAR data. Remote Sens. Environ. 2016, 182, 1-12. [CrossRef]

94. White, J.C.; Wulder, M.A.; Buckmaster, G. Validating estimates of merchantable volume from airborne laser scanning (ALS) data using weight scale data. For. Chron. 2014, 90, 378-385. [CrossRef]

95. Drake, J.B.; Dubayah, R.O.; Clark, D.B.; Knox, R.G.; Blair, J.B.; Hofton, M.A.; Chazdon, R.L.; Weishampel, J.F.; Prince, S. Estimation of tropical forest structural characteristics, using large-footprint lidar. Remote Sens. Environ. 2002, 79, 305-319. [CrossRef]

96. Sun, G.; Ranson, K.J.; Kimes, D.S.; Blair, J.B.; Kovacs, K. Forest vertical structure from GLAS: An evaluation using LVIS and SRTM data. Remote Sens. Environ. 2008, 112, 107-117. [CrossRef]

97. Thomas, V.; Treitz, P.; McCaughey, J.H.; Morrison, I. Mapping stand-level forest biophysical variables for a mixedwood boreal forest using lidar: An examination of scanning density. Can. J. For. Res. 2006, 36, $34-47$. [CrossRef]

98. Hilker, T.; van Leeuwen, M.; Coops, N.C.; Wulder, M.A.; Newnham, G.J.; Jupp, D.L.B.; Culvenor, D.S. Comparing canopy metrics derived from terrestrial and airborne laser scanning in a Douglas-fir dominated forest stand. Trees Struct. Funct. 2010, 24, 819-832. [CrossRef]

99. Dawson, T.P.; North, P.R.J.; Plummer, S.E.; Curran, P.J. Forest ecosystem chlorophyll content: Implications for remotely sensed estimates of net primary productivity. Int. J. Remote Sens. 2003, 24, 611-617. [CrossRef]

100. Elvidge, C.D.; Chen, Z. Comparison of broad-band and narrow-band red and near-infrared vegetation indices. Remote Sens. Environ. 1995, 54, 38-48. [CrossRef]

101. Wang, Q.; Pang, Y.; Li, Z.; Sun, G.; Chen, E.; Ni-Meister, W. The potential of forest biomass inversion based on vegetation indices using multi-angle CHRIS/PROBA data. Remote Sens. 2016, 8, 891. [CrossRef]

102. Jiang, B.; Yuan, W.; Zhu, G.; Shi, J.; Zhao, P.; Xu, Z. A preliminary study on the plantation biomass and produce structure of Pinus massoniana, Pinus elliottii and Pinus taeda. J. Zhejiang For. Sci. Technol. 1992, 12, 1-9.

103. Ye, J.; Jiang, Z. Biomass structure of planted Chinese fir in Southern Jiangsu province, China. Acta Ecol. Sin. 1983, 3, 7-14.

104. Wang, Q.; Shi, Y. A preliminary study on the biomass and production of slash pine plantation in Jiangsu province. Acta Phytoecol. Geobot. Sin. 1990, 14, 2-12.

105. Xu, J.; Wang, M.; Huang, Q. Study on aboveground biomass model of natural individual trees of Quercus acutissima. Anhui For. Sci. Technol. 2011, 37, 3-6.

106. Qian, G. Studies on the dynamic change of the net production quantity of liquidambar formosana plantation. Acta Agric. Univ. Jiangxiensis 2000, 22, 399-404.

107. Sun, D.; Ruan, H.; Ye, J. Biomass structure of oak-dominated secondary forest in kongqingshan. In Proceedings of Xiashu Forest Ecological System; China Forestry Publishing House: Beijing, China, 1992; pp. 16-22. 
108. Zhao, H.; Zhang, J.; Zhang, M.; Shao, C.; Fang, Y.; Chen, G. Establishment on multivariate mixed effects standard stand volume model of Pinus massoniana Lamb trees in Nanjing area. J. Cent. South Univ. For. Technol. 2015, 35, 40-45.

109. Zeng, W. Establishment of Compatible Tree Volume Equation Systems of Chinese Fir. For. Res. 2014, $27,6-10$.

110. Xu, Y.; Bao, L. Establishment of binary volume equation of Slash pine in Hubei province. Hubei For. Sci. Technol. $1999,4,9$.

111. Cheng, W.; Feng, Z.; Yu, J. Development of Generic Standard Volume Model and Derived Form Factor Model for Major Tree Species in China. Trans. Chin. Soc. Agric. Mach. 2017, 48, 245-252.

112. Huang, Q. Growth and soil physical-chemical character of mixed forest of Cunninghamia lanceolate and Liquidambar formosana. Prot. For. Sci. Technol. 2017, 12, 35-37.

(C) 2018 by the authors. Licensee MDPI, Basel, Switzerland. This article is an open access article distributed under the terms and conditions of the Creative Commons Attribution (CC BY) license (http://creativecommons.org/licenses/by/4.0/). 